\title{
O-Fucose Modulates Notch-Controlled Blood Lineage Commitment
}

\author{
Quanjian Yan, ${ }^{*}$ David Yao, ${ }^{*}$ Lebing L. Wei, ${ }^{*}$ \\ Yuanshuai Huang, ${ }^{*}$ Jay Myers, ${ }^{*}$ Lihua Zhang, ${ }^{*}$ \\ Wei Xin, ${ }^{*}$ Jeongsup Shim, ${ }^{\dagger}$ Yunfang Man, ${ }^{*}$ \\ Bronislawa Petryniak, ${ }^{\dagger}$ Stanton Gerson, ${ }^{\neq}$ \\ John B. Lowe, ${ }^{\dagger}$ and Lan Zhou* \\ From the Department of Pathology, and the Case Comprebensive \\ Cancer Center, ${ }^{\ddagger}$ Case Western Reserve University, Cleveland, \\ Obio; and the Department of Patbology, ${ }^{\dagger}$ Genentech, Inc., South \\ San Francisco, California
}

Notch receptors are cell surface molecules essential for cell fate determination. Notch signaling is subject to tight regulation at multiple levels, including the posttranslational modification of Notch receptors by $O$-linked fucosylation, a reaction that is catalyzed by protein $O$-fucosyltransferase-1 (Pofut1). Our previous studies identified a myeloproliferative phenotype in mice conditionally deficient in cellular fucosylation that is attributable to a loss of Notch-dependent suppression of myelopoiesis. Here, we report that hematopoietic stem cells deficient in cellular fucosylation display decreased frequency and defective repopulating ability as well as decreased lymphoid but increased myeloid developmental potential. This phenotype may be attributed to suppressed Notch ligand binding and reduced downstream signaling of Notch activity in hematopoietic stem cells. Consistent with this finding, we further demonstrate that mouse embryonic stem cells deficient in Notch1 $\left(\right.$ Notch $\left.^{-/}\right)$or Pofut1 (Pofut $1^{-/-}$) fail to generate T lymphocytes but differentiate into myeloid cells while coculturing with Notch ligand-expressing bone marrow stromal cells in vitro. Moreover, in vivo hematopoietic reconstitution of $\mathrm{CD}_{3} 4^{+}$progenitor cells derived from either Notch1 $1^{-1-}$ or Pofut ${ }^{-/-}$embryonic stem cells show enhanced granulopoiesis with depressed lymphoid lineage development. Together, these results indicate that Notch signaling maintains hematopoietic lineage homeostasis by promoting lymphoid development and suppressing overt myelopoiesis, in part through processes controlled by $O$-linked fucosylation of Notch receptors. (Am J Pathol 2010, 176:2921-2934; DOI: 10.2353/ajpath.2010.090702)
Notch signaling is essential for T cell commitment and development. ${ }^{1,2}$ Intracellular signaling mediated by Notch also plays a key role in maintaining various stem cell systems. ${ }^{3}$ Studies have shown that Notch activation by the exogenous Notch ligands promotes hematopoietic stem cell (HSC) expansion in vitro and favors lymphoid over myeloid lineage outcome in vivo. ${ }^{4-7}$ More recently, Calvi et al demonstrated that Notch activation by Notch ligand-expressing osteoblasts in bone marrow promotes self-renewal of primitive hematopoietic cells. ${ }^{8}$ These observations identify Notch as an essential component of bone marrow niche that supports HSC function. In comparison, Notch1 and/or Jagged1 loss-of-function studies using targeted gene ablation, or expression of a dominant negative inhibitor of canonical Notch activation, did not reveal an essential role of Notch in HSC self-renewal. ${ }^{9-11}$ To reconcile these two findings, we hypothesize that the interaction between other Notch receptor and Notch ligand pairs upstream of Notch intracellular signaling, or aspects of Notch pathways in the absence of fucose that are independent of the transcriptional control of Notch signaling mediated by Mastermind-like 1, may be critical for HSC biology. Further, the role of Notch and Notch ligand interaction or Notch signaling transduction in lymphoid versus myeloid fate commitment of HSC has not been defined.

Notch signaling is subject to multiple regulating events that modify Notch-Notch ligand interactions or intracellular signaling. O-linked fucose attached to the epidermal growth factor (EGF)-like repeats of Notch receptors can modulate Notch signaling. Additionally, Fringe-mediated extension of O-fucose can differentially influence Notch signaling in Drosophila development, in murine embryo-

Supported in part by grants from the National Blood Foundation Research grant, the Ohio Cancer Research grant, and K08 HL089218 (to L.Z.) and 1P01CA71932 (to J.B.L.)

Q.Y. and D.Y. contributed equally to this study.

J.B.L. and L.Z. share the senior authorship on this article.

Accepted for publication January 27, 2010

Supplemental material for this article can be found on http://ajp. amjpathol.org

Address reprint requests to Lan Zhou, M.D., Ph.D., Department of Pathology, Case Western Reserve University, Cleveland, OH 44106. E-mail: Ian. zhou@case.edu. 
genesis, and T lymphopoiesis. ${ }^{12-14}$ Recently we reported that mice carrying a targeted deficiency in the FX locus, of which gene encodes an enzyme that converts GDPmannose to GDP-fucose in the de novo fucose synthesis pathway, develop chronic myeloproliferation. This faulty myeloid development is a result of loss of controlled suppression of myelopoiesis exerted by Notch, and that protein O-fucosylation modulates these Notch-dependent processes by controlling the interactions between Notch and its ligands. ${ }^{15}$

Mice with fucose deficiency also exhibit thymic hypoplasia and shortened survival of unknown causes. Expansion of the myeloid compartment is accompanied by a decreased common lymphoid progenitor (CLP) compartment. ${ }^{15}$ Given the evidence that Notch is important for HSC function, we speculate that fucosylation-modulated Notch signaling does not only regulate myelopoiesis of committed myeloid progenitors but also may affect HSC biology, particularly during early myeloid versus lymphoid diversification. We now report that HSC from fucose-deficient mice display suppressed Notch signaling and decreased self-renewal. Marrow cells isolated from fucose-deprived mice are less effective than wildtype cells, or cells from fucose-repleted $F X^{-1-}$ mice, in competitive repopulation transplant assays. These cells, however, exhibit an enhanced myelopoietic phenotype after engraftment. The enhanced myelopoiesis from marrow progenitors can be partially suppressed by the expression of the activated Notch1 intracellular domain. Further, using both in vitro mouse embryonic stem cell (ESC) hematopoietic differentiation assay and in vivo hematopoietic reconstitution, we observe that Notch activation promotes T lymphopoiesis while suppressing myelopoiesis. These processes of ES hematopoiesis appear to be dependent on both Notch1 activity and O-fucose modification, as absence of Notch1 or loss of fucosylation leads to suppressed T lymphopoiesis and enhanced myelopoiesis in vitro, as well as an aberrant blood lineage development in vivo characterized by an expansion of the myeloid compartment and suppressed lymphoid reconstitution.

\section{Materials and Methods}

\section{Animals and ES Cell Lines}

The animal research related to this article was approved by Case Western Reserve University Institutional Animal Care and Use Committee. Mice used include 8- to 18week-old wild-type and $F X^{-1-}$ mice maintained and prepared as described. ${ }^{16}$ The Notch reporter transgenic (NTg) mouse was purchased from the Jackson Laboratory (stock \# 005854, Bar Harbor, Maine). FX ${ }^{-1-}$-NTg mouse was generated by crossing the NTg with the $\mathrm{FX}^{-1-}$ mouse. Notch1 ${ }^{-1-}$ ES cell lines were kindly provided by Dr. Rafel Kopan (Washington University School of Medicine, St. Louis, MO). Pofut1 ${ }^{-1-}$ ES cells were kindly provided by Dr. Pamela Stanley (Albert Einstein College of Medicine, New York, NY). The Pofut2 ${ }^{-1-}$ mouse ES line was generated from blastocyst out- growths of Pofut2 heterozygotes crossed at the Case Transgenic \& Targeting Facility (BayGenomics, ES cell line RST434). The genotype was confirmed by PCR.

\section{Flow Cytometry Analysis and Cell Sorting}

Flow cytometric analyses were performed as described. ${ }^{15}$ When isolating multipotent progenitor cells (MPP) $\left(\mathrm{Lin}^{-} \mathrm{Scal}^{+} \mathrm{C}-\mathrm{kit}^{+} \mathrm{Flt}^{+}\right)$, lineage-depleted cells were further stained with streptavidin-allophycocyanin (APC)-Cy7, fluorescein isothiocyante (FITC)-antiSca-1, phycoerythrin (PE)-anti-FIt3, and APC-anti-c-kit, and sorted using FACSAria (BD Biosciences, San Jose, CA).

\section{CFU Assay and MPP in Vitro Culture}

For single CFU assays, single $\mathrm{Lin}^{-} \mathrm{Scal}^{+} \mathrm{C}^{-\mathrm{kit}^{+}}$(LSK) cells were sorted into 96-well plates containing methylcellulose (MethoCult M3434, StemCell Technologies, Vancouver, BC, Canada). For pre-B CFU assay, bone marrow (BM) cells were plated onto plates containing MethoCult M3630 (MethoCult M3630, StemCell Technologies, Vancouver, BC, Canada). In OP9 co-culture assays, MPPs from wild-type and $F X^{-1-}$ mice were cultured for 28 days on OP9-control or OP9-Notch ligand expressing cells in the presence of $\mathrm{rmlL}-7(5 \mathrm{ng} / \mathrm{ml})$ and $\mathrm{rmFlt3L}$ ( $5 \mathrm{ng} / \mathrm{ml}$; R\&D Systems, Minneapolis, MN) and analyzed at the end of culture as described. ${ }^{15}$

\section{Bone Marrow Transplantation and Competitive Repopulation Assays}

Bone marrow transplant was performed as described. ${ }^{15}$ For competitive repopulation assays, BM nucleated cells from wild-type or $F X^{-1-}$ mice (Ly5.2) were mixed with wild-type competitor cells (Ly5.1) in a ratio of 1:3, 1:1, and $3: 1\left(1.8 \times 10^{6}\right.$ total cells per mouse $)$ and transplanted into lethal-irradiated wild-type recipients (Ly5.1). Peripheral blood was collected from the recipients at 12 to 16 weeks to investigate the percentage of test cells based on Ly5.2 expression and different lineage contributions.

\section{ES Cell in Vitro Hematopoietic Differentiation}

ES cells $\left(8 \times 10^{3}\right)$ were cultured on Iscove modified Dulbecco medium containing 1\% methylcellulose (M03120, StemCell Technologies) and $40 \mathrm{ng} / \mathrm{ml}$ stem cell factor (R\&D Systems, Minneapolis, MN) as described. ${ }^{17}$ After 7 to 10 days, the embryoid bodies were removed, and $\mathrm{CD}_{3}{ }^{+}$cells were isolated by biotinylated rat anti-mouse CD34 and anti-biotin-beads (Miltenyi, Auburn, CA). These cells were then seeded onto OP9-control or OP9Notch ligand-expressing cells in the presence of rmFlt3 ligand and $\mathrm{rmlL}-7 .{ }^{18}$ Cells were recovered from the day 15 culture and analyzed by FITC-anti-CD11b or CD25; PE-anti-Ter119 or CD44; APC-anti-B220 or CD4; APCCy7-anti-CD8; and PE-Cy7-anti-CD45 (BD Biosciences, 
San Jose, CA). Cell surface expression of Notch receptors in $\mathrm{CD}_{3} 4^{+} \mathrm{HPCs}$ was characterized by staining cells with PE-conjugated anti-Notch1, Notch2, Notch3, and Notch4 antibodies (Biolegend, San Diego, CA).

\section{In Vivo Assessment of ESC-Derived Hematopoietic Development by Intrafemoral Transplantation and Intrathymic Transplantation}

ESCs were induced to differentiate toward hematopoiesis as described above. A single cell suspension of CD34 ${ }^{+}$ cells $\left(10^{5}\right.$ cells per $\left.20 \mu \mathrm{l}\right)$ was used for intrafemoral injection. Recipients (Ly5.1) were sublethally (5.5 Gy) or lethally irradiated (9.5 Gy) 24 hours before injection as described. ${ }^{19}$ The presence of donor-derived (ESC-Ly5.2) $T, B$, and granulocytes was determined by flow analysis of peripheral blood collected 2, 4, 8, 12 weeks, and monthly after injection. Of a total of 74 mice injected, only one mouse developed teratoma. No mice showed signs of weight loss or hunched back, which are suggestive of graft-versus-host disease. For intrathymic transplantation, CD34 ${ }^{+}$cells $\left(10^{5}\right.$ cells/20 $\mu$ l) were injected into thymic lobes of anesthetized $F X^{-1-}$ mice (maintained on fucose-supplemented chow until 8 week of age and then maintained on standard chow for 10 to 14 days). T lymphopoiesis was analyzed by flow cytometry on total thymocytes collected 2 weeks after transplantation.

\section{Recombinant Mouse Notch Ligand Binding Assays}

Recombinant Notch ligand comprising the extracellular domains of Dll1 or Dll4 fused with human IgG Fc were constructed as described. ${ }^{20}$ Recombinant Notch ligand was prepared from HEK 293 T cells transfected with hlgG-DII1, DII4, or the vector and quantified by ELISA. ${ }^{15}$ Binding assay was performed by incubating LSK cells or ES cells with recombinant Notch ligand in Hanks balanced salt solutions supplemented with $\mathrm{Ca}^{2+}$ and analyzed by FACS using PE-anti-human IgG FC.

\section{Generation and Bone Marrow Infection of Activated Notch1-Expressing Retrovirus}

To generate retrovirus containing constitutive active Notch1 molecules (ICN1), Phoenix E cells were transiently transfected with either pMig (kindly provided by Dr. Luk Van Parijs at Massachusetts Institute of Technology Center for Cancer Research, Cambridge, MA), or pMig-ICN1 using the Profection mammalian transfection system according to the manufacturer's specifications (Promega, Madison, WI). Notch1 intracellular domain (ICN1; 1735-2531) was inserted into pMig, a vector that allows coexpression of cloned cDNA and green fluorescent protein (GFP) from a single bicistronic message, to form pMig-ICN1-GFP. Viral supernatants were collected on three consecutive days 24 hours after the transfection. Infection of each viral vector on bone marrow progenitors was performed as described. ${ }^{21}$ Briefly, $F X^{-1-}$ mice mar- row cells were collected 4 days after 5 -FU treatment and cultured in a 6-well plate in the growth medium (DMEM supplemented with $10 \%$ of FBS, $6 \mathrm{ng} / \mathrm{ml}$ of IL3, $10 \mathrm{ng} / \mathrm{ml}$ of IL6, and $10 \mathrm{ng} / \mathrm{ml}$ of stem cell factor) for 24 hours. Infections were performed on $1 \times 10^{6}$ bone marrow progenitors per well in $1.5 \mathrm{ml}$ of growth medium containing $4 \mu \mathrm{g} / \mathrm{ml}$ of polybrene using $1.5 \mathrm{ml}$ of each viral supernatant. A second infection was performed 24 hours after the initial infection. Forty-eight hours after the secondary infection, cells were harvested for bone marrow transplant. Approximately $2 \times 10^{6}$ cells were injected into the tail veins of lethally irradiated syngeneic wild-type recipient mice. Recipients were sacrificed at the indicated time, and single-cell suspensions were prepared from peripheral blood, BM, and spleens.

\section{Statistical Analysis}

Data are presented as means \pm SD, unless otherwise stated. Statistical significance was assessed by Student $t$ test.

\section{Results}

Decreased HSC Frequency and Lymphoid

Progenitor Populations in $\mathrm{FX}^{-1-}$ Mice, Accompanied by Suppressed Notch Activation

Notch signaling strength can be modified by O-fucose that is present on Notch EGF repeats. ${ }^{22-25}$ We recently identified that $\mathrm{O}$-fucosylation of Notch receptors is required for the Notch receptor-ligand interaction on myeloid progenitor cells and thus suggests a requirement for O-fucosylation in normal control of myelopoiesis. ${ }^{15}$ To examine whether $\mathrm{O}$-fucosylation of Notch modulates HSC biology, we first assessed the frequency of LSK $\left(\mathrm{Lin}^{-} \mathrm{Sca}-1^{+} \mathrm{C}-\mathrm{kit}^{+}\right)$cells in $\mathrm{FX}^{-1-}$ mice that are deficient in GDP-fucose synthesis. Flow cytometric analysis indicates that there is a twofold decrease in the LSK percentage in the marrows of $F X^{-1-}$ mice at steady state. A large proportion of this decrement was accounted for by a decrease in the percentage of MPPs (Flt3 ${ }^{+}$LSK; Figure $1 \mathrm{~A})$. This change in the HSC population was confirmed by CFU analysis, which revealed that $F X^{-1-}$ mice have a decreased number of granulocyte/erythrocyte/monocyte/ megakaryocyte-CFU (mix-CFU; Figure 1B). To further examine the stem cell frequency in $\mathrm{FX}^{-1-}$ marrow, we performed limiting-dilution assays using a common wild-type marrow competitor (Ly5.1; Table 1). FX ${ }^{-1-}$ mice had a 13.7-fold reduction of stem cell frequency relative to wildtype mice after myeloablative transplantation. Individual LSKs from $F X^{-1-}$ mice also displayed a decreased ability to form multilineage colonies but an increased frequency of single-lineage myeloid colonies when compared with wild-type LSKs (Figure 1C). Furthermore, marrow cells from $F X^{-1-}$ mice formed a reduced number of pre-B cell colonies (Figure 1, C and D). This finding is consistent with our prior reports that $F X^{-1-}$ mice have reduced CLP numbers. ${ }^{15}$ In comparison, $\mathrm{FX}^{-1-}$ mice maintained on 

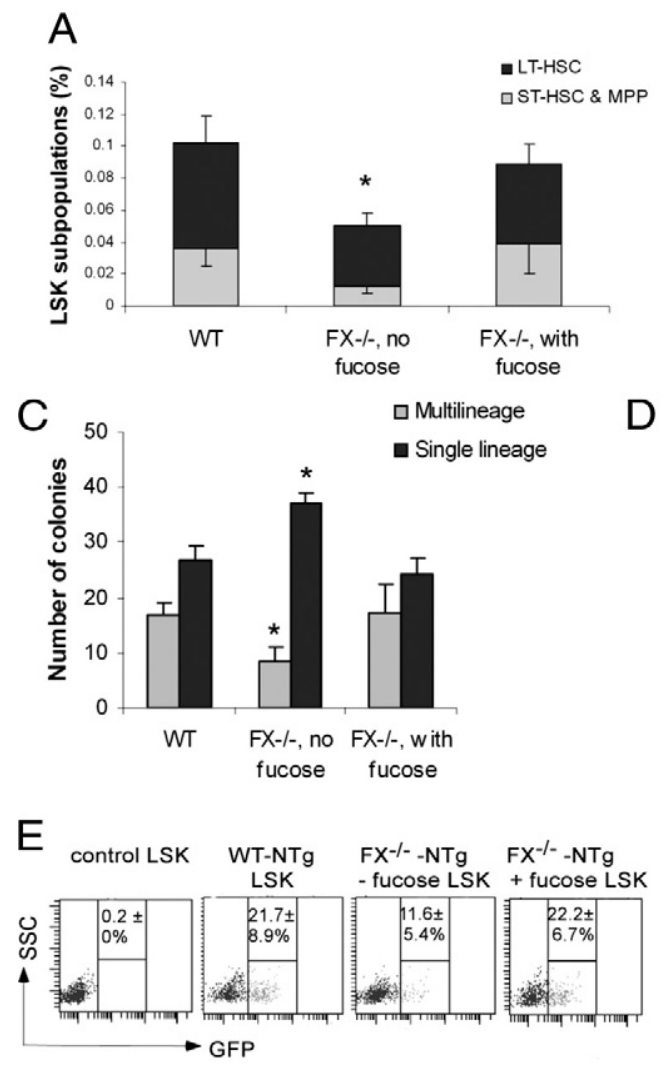
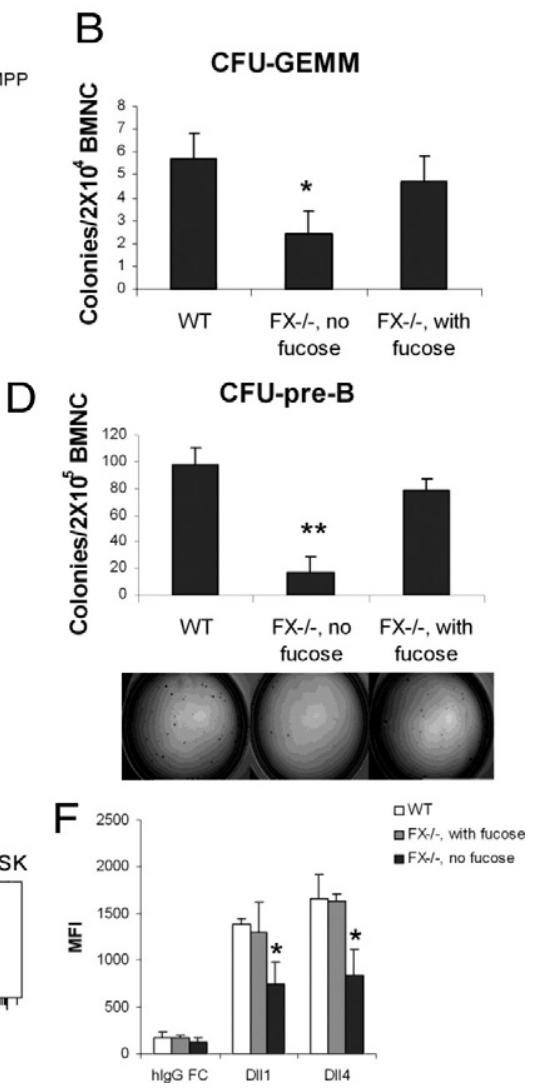

Figure 1. $\mathrm{FX}^{-/-}$mice have decreased HSC and lymphoid progenitors and LSK have suppressed Notch activation. A: FACS analysis of the HSC compartment (LT \& ST-HSC: $\mathrm{Lin}^{-} \mathrm{C}^{-\mathrm{kit}^{+}}{ }^{+} \mathrm{Sca}-$ $1^{+} \mathrm{Flt} 3^{-}$; MPP: Lin $^{-} \mathrm{C}-\mathrm{kit}^{+} \mathrm{Sca}-1^{+} \mathrm{Flt} 3^{+}$) in the bone marrow in 3- to 4-month-old control mice (wild-type: WT; $n=8$ ). $F X^{-1}$ mice were reared on fucose-supplemented chow until 12 weeks of age and then on standard chow for at least four weeks ( $n=8 ; F X^{-1-}$, no fucose), and $F X^{-1-}$ mice were reared on fucose-supplement chow until use ( $n=8 ; \mathrm{FX}^{--}$, with fucose). Bar graphs indicate the average total number of LT \&ST-HSC and MPP cells from two tibias and two femurs of each mouse. B: CFU-Mix numbers as colonies per $2 \times 10^{4}$ BMNC (wild-type, $n=6$; $\mathrm{FX}^{-1-}$, no fucose, $n=6 ; \mathrm{FX}^{-1-}$, with fucose, $n=6)$. C: Multilineage or single myeloid lineage colonies formed by single LSK cells in 96-well plates (wild-type, $n=4 ; F X^{-1-}$, no fucose, $n=$ 4; $F X^{-1-}$, with fucose, $\left.n=4\right)$. D: Number of CFU-preB colonies per $2 \times 10^{5}$ BMNC (wildtype, $n=4 ; F X^{-1-}$, no fucose, $n=4 ; F X^{-/-}$. with fucose, $n=4)$. E: FACS analysis of bone marrow LSK cells displaying GFP signal in wildtype-NTg and $\mathrm{FX}^{-1-}$-NTg mice. F: FACS analysis of binding of recombinant Notch ligands, Dll1 $(1.3 \mu \mathrm{Mg} / \mathrm{ml})$, Dll4 $(0.5 \mu \mathrm{g} / \mathrm{ml})$, and control (human IgG1 Fc, $1 \mu \mathrm{g} / \mathrm{ml}$ ), to LSK cells isolated from wild-type mice, from $\mathrm{FX}^{-1-}$ mice reared in the presence of fucose, or from $\mathrm{FX}^{-/}$mice reared in the absence of fucose. The bar graph shown is one representative of the mean fluorescence intensity (MFI) of the binding of LSKs with control and Notch ligands (D111 and D114) from three independent experiments. ${ }^{*} P<0.05$, ${ }^{* * *} P<0.01$ fucose-supplemented chow had normal frequencies of LSK subpopulations and pre-B cells. These findings indicate that fucose-deficiency results in marrow myeloproliferation that is accompanied by a suppressed HSC compartment and a severely suppressed lymphoid progenitor compartment.

To correlate Notch activation in fucose-deficient HSC with HSC numbers, we used a Notch reporter transgenic (NTg) mouse to examine whether fucosylation-deficient progenitors display a down-regulated Notch signaling phenotype. The NTg mouse carries a hemizygous allele of Notch-signaling CBF-1 response element and a minimal SV40 promoter driven enhanced green fluorescent protein (eGFP). This mouse has been used to define active Notch signaling in HSCs in vivo. ${ }^{26}$ We found that $22 \%$ of wild-type LSKs were GFP ${ }^{+}$, whereas only $11.6 \%$ of fucose-depleted LSKs from $F X^{-1-}$-NTg mice were $\mathrm{GFP}^{+}$. The number of $\mathrm{GFP}^{+}$LSKs was restored to the wild-type level when mice were reared on a fucose-supplemented diet (Figure 1E). These observations are consistent with our prior observations that Notch signaling is suppressed in HSCs and progenitors as a result of fucosylation deficiency. ${ }^{15}$ We then determined whether there is a similar fucosylation-dependent requirement for ligand binding to HSCs as for myeloid progenitors. We found that recombinant DII4 and DII1 ligands bound to wild-type LSKs with mean fluorescence intensity (MFI) of 1401 and 1728, respectively, whereas the MFI of human

Table 1. Competitive Limiting Dilutions of Wild-Type and $\mathrm{FX}^{-1-}$ Marrow HSC

\begin{tabular}{|c|c|c|c|c|}
\hline Donor HSC & $\begin{array}{l}\text { Cell dose } \\
\text { injected }\end{array}$ & $\begin{array}{l}\text { Calculated number } \\
\text { of LSK cells injected }\end{array}$ & $\begin{array}{l}\text { Number of mice engrafted/ } \\
\text { number of mice injected }\end{array}$ & $\begin{array}{l}\text { HSC frequency ( } \pm 95 \% \\
\text { confidence interval) }\end{array}$ \\
\hline Wild-type & $\begin{array}{r}5 \times 10^{5} \\
5 \times 10^{4} \\
2.5 \times 10^{4} \\
5 \times 10^{3}\end{array}$ & $\begin{array}{r}500 \\
50 \\
25 \\
5\end{array}$ & $\begin{array}{l}6 / 6 \\
7 / 7 \\
6 / 8 \\
1 / 8\end{array}$ & $1 / 17,631$ (9660 to 32,179$)$ \\
\hline$F X^{-1-}$ & $\begin{array}{r}5 \times 10^{5} \\
5 \times 10^{4} \\
2.5 \times 10^{4} \\
5 \times 10^{3}\end{array}$ & $\begin{array}{r}260 \\
26 \\
13 \\
3\end{array}$ & $\begin{array}{l}6 / 6 \\
0 / 5 \\
1 / 9 \\
0 / 13\end{array}$ & $1 / 240,741(96,151$ to 602,764$)$ \\
\hline
\end{tabular}

Bone marrow cells were isolated from $\mathrm{FX}^{-1-}$ and wild-type mice and were transplanted into lethally irradiated CD45. 1 recipient mice along with $5 \times$ $10^{5}$ CD45.1 competitor cells. Numbers of LSK cells injected are calculated based on their frequency in the marrow of FX-1- and wild-type mice. Shown are cumulative data from three separate transplant experiments. Donor engraftment was determined by FACS analysis on peripheral blood leukocytes. Donor engraftment was defined as $>5 \%$ in myeloid $\mathrm{Gr}-1^{+}$and lymphoid $\mathrm{B} 220^{+}$lineages. The cell dose at which $37 \%$ of mice tested were negative for donor multi-lineage engraftment at 12 weeks was used to calculate the frequency of HSC based on Poisson statistics using L-Calc software (StemCell Technologies). $P<0.01$ by two-tailed Student $t$ test. 
A
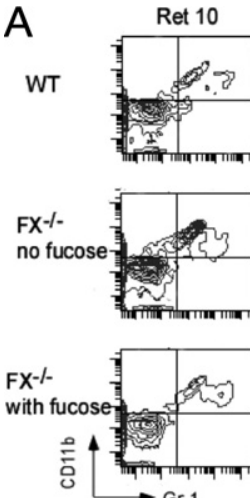

C

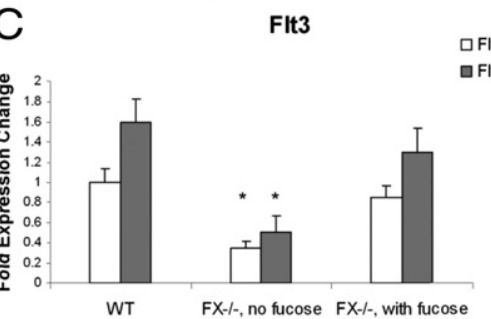

E

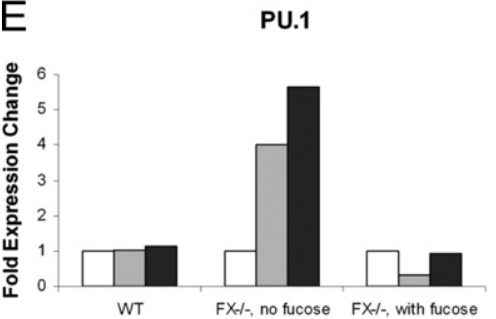

B

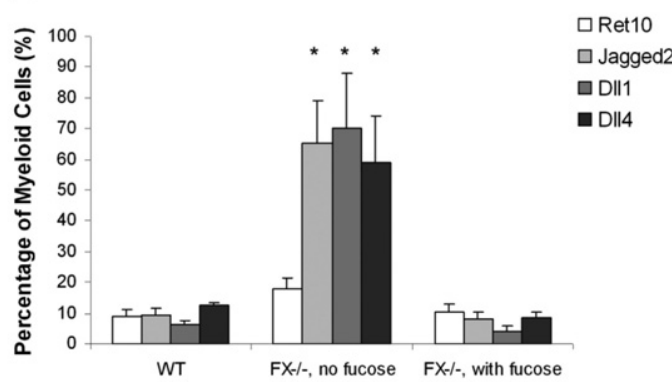

\section{$\square \operatorname{Ret} 10$}

FIt3-LSK

\section{$D$}

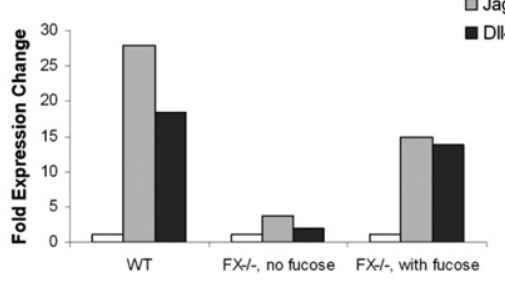

- DII4

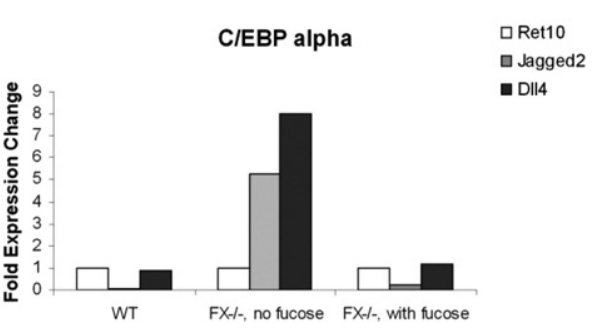

Figure 2. Enhanced myelopoiesis and suppressed lymphopoiesis from MPP cells from $\mathrm{FX}^{-1}$ mice. A: A representative flow cytometry dot plot analysis on day 21 of culture of bone marrow-derived MPP cells, cocultured with OP9-control cells (no ligand) or OP9-Dll1, for Gr-1 and CD11b expression. B: Data shown are mean values of at least four determinations. The bar graph indicates percentage of myeloid cells (expressing Gr-1 or CD11b) among total viable cells. C-E: Quantitative RT-PCR analysis of Flt3 expression in total Flt ${ }^{-}$LSK and Flt $3^{+}$LSK cells (C), GATA-3 expression (D), and PU.1 and $C / E B P \alpha$ expression (E) on day 21 cultured MPP cells. Results of Flt3 (mean $\pm \mathrm{SD} ; n=3$ ) or GATA-3/PU.1/C/EBPQ (one representative of three similar experiments) have been standardized for GAPDH levels and were expressed as fold expression change relative to the levels detected in wild-type Flt $3^{-}$LSK cells $(\mathbf{C})$ or MPPs in OP9-Ret10 cultures (D and $\mathbf{E}$; set at 1$) .{ }^{*} P<0.05$ versus wild-type cell numbers or expression level.
IgG Fc staining was 218 (Figure 1F). LSKs from fucoserepleted $F X^{-1-}$ mice exhibited a wild-type binding phenotype. In contrast, we observed an approximately 50\% reduction in the binding of these recombinant ligands to fucose-depleted LSKs. These observations indicate that the decreased Notch signaling in fucose-depleted LSKs is accompanied by a loss of effective binding of Notch ligands to these cells.

\section{Fucose-Deficiency Promotes Multipotent Progenitors to Adopt Myeloid Fate at the Expense of Lymphoid Specification}

It has been shown that the up-regulation of Flt3 confers a primed lymphoid potential in marrow MPPs (Flt3 ${ }^{+}$LSK), ${ }^{27,28}$ and the suppression of myeloid differentiation potential is required for $\mathrm{T}$ cell commitment. ${ }^{29}$ To explore the underlying mechanism of the increase in myeloid progenitors and the decrease in lymphoid progenitors in fucose-deficient mice, we sought to examine the myeloid versus lymphoid development potential of MPPs in response to Notch activation.

By using a coculture system, Schmitt et al has shown that Notch ligand-expressing OP9 stromal cells support a robust generation of $\mathrm{CD}^{+}{ }^{+} \mathrm{CD} 8^{+}(\mathrm{DP}) \mathrm{T}$ cells from hematopoietic progenitors. ${ }^{30}$ Further, the T Iymphopoietic potential of LSKs is fucosylation dependent, as LSKs from $F X^{-1-}$ marrow lost their T cell differentiation ability. ${ }^{31}$ Sim- ilarly, we observed that when cultured on OP9s expressing Notch ligand (Jagged2, DII1, or DII4), wild-type MPPs generated robust DP T cells (data not shown) but minimal granulocytes. In contrast, when culturing with Notchligand bearing OP9s, $\mathrm{FX}^{-1-}$ MPPs differentiated into those primarily of the myeloid lineage ( $>50 \%$ express Gr-1 or CD11b; see Figure 2, A and B), whereas others expressed early immature $\mathrm{T}$ cell markers at DN1 stage (data not shown).

To further explore the underlying mechanism of the increased myeloid development potential of fucosylationdeficient MPPs, we examined the expression of Flt3 receptor, ${ }^{28}$ and GATA-3, a T-cell transcription factor that is known to be regulated by Notch, ${ }^{30}$ in both freshly-isolated and cultured MPPs after their exposure to Notch ligands. We observed that the expression of Flt3 mRNA in freshly-isolated $\mathrm{Flt}^{+}{ }^{+} \mathrm{LSK}$ and $\mathrm{Flt} 3^{-} \mathrm{LSK}$ from $\mathrm{FX}^{-1-}$ mice was only $40 \%$ and $50 \%$, respectively of that seen in wild-type subpopulations. The expression of Flt3 was not significantly changed in fucose-repleted LSKs (Figure 2C). Wild-type cells taken from day 10 OP9 cultures in the presence of Jagged2 and DII4 exhibited 18.4- and 27.9fold increases in GATA-3 expression, respectively (Figure 2D). In comparison, cultured MPPs taken from fucose-deprived $F X^{-1-}$ mice showed minimal increases in GATA-3 expression when interacting with DII4 and Jagged 2 (3.7- and 2-fold increases, respectively). This 


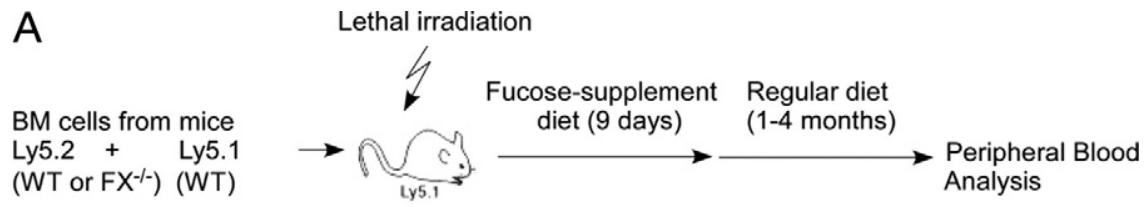

3 (donor $25 \%$ )

1 (donor $75 \%$ )
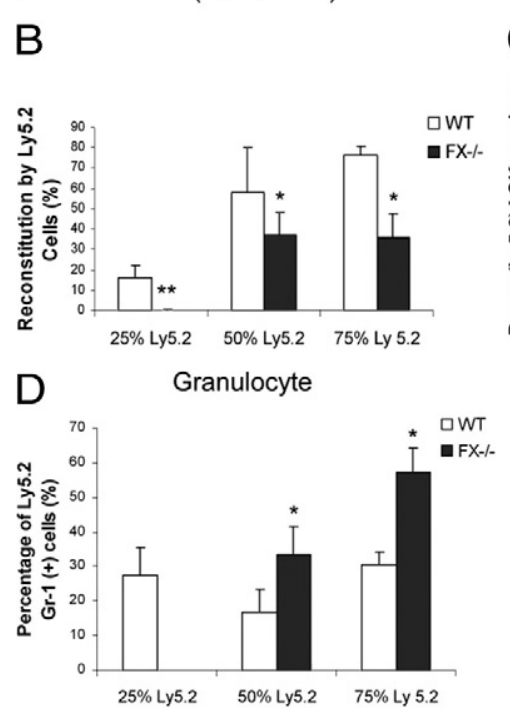

C
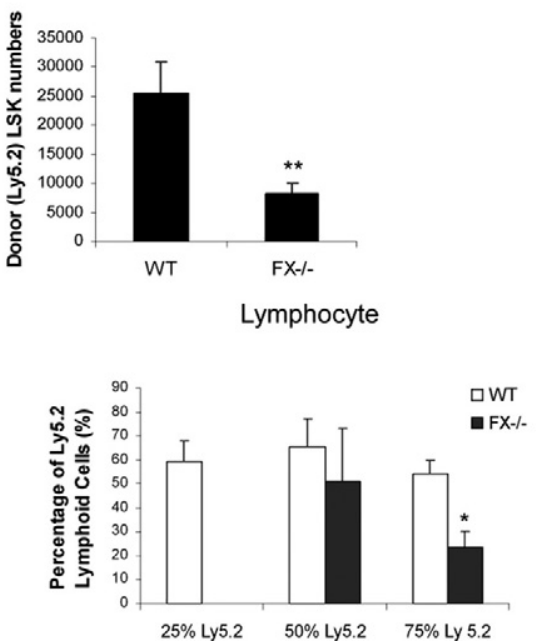

Figure 3. $F X^{-1-} \mathrm{HSC}$ have impaired repopulating ability and enhanced myelopoiesis and suppressed lymphopoiesis in vivo. A: Schematic representation of the competitive transplantation protocol. B: Reconstitution of peripheral blood by Ly5.2 cells 12 weeks after transplantation. Reconstitution is calculated as the percentage of testing cells (Ly5.2) of total peripheral blood mononuclear cells (Ly5.2 + Ly 5.1) after red cell lysis. C: Absolute numbers of LSK cells derived from testing cells (Ly5.2) in the recipient bone marrow of each mouse receiving 1:1 of testing (wild-type or $\mathrm{FX}^{-1}$ ) versus competing cells (wild-type, $n=4 ; F X^{-1-}, n=4$ ). D: Percentage of neutrophils $\left(\mathrm{Gr}-1^{+}\right)$and lymphocytes $\left(\mathrm{B} 220^{+}\right.$ and $\left.\mathrm{CD} 3 \varepsilon^{+}\right)$in Ly5.2 cells by FACS 12 weeks after competitive transplantation in recipient mice. Data shown are mean values \pm SD. A Student $t$ test was performed to compare the percentage of neutrophils or lymphocytes in transplant setting receiving $\mathrm{FX}^{-1}$ cells with those of wild-type cells. ${ }^{*} P<0.05,{ }^{* * *} P<0.01$. phenotype was rescued when fucose-repleted MPPs were cultured in the presence of exogenous fucose where GATA-3 expression was increased by 13.9- to 14.9-fold. Furthermore, we observed that the expression of myeloid transcription factors, PU. 1 and $\mathrm{C} / \mathrm{EBP} \alpha$, remained unchanged or was suppressed on Notch ligand stimulation in wild-type or fucose-repleted MPP cells, whereas their expressions were increased four- to eightfold in fucose-depleted MPPs when compared with that in cells from cultures without Notch ligand (Figure 2E). Together, these observations suggest that the reduced $T$ lymphoid and increased myeloid potential associated in fucose-depleted LSKs is partly attributable to a suppressed expression of lymphoid-priming transcription factors that are normally up-regulated, and a sustained expression of myeloid transcription factors that are normally down-regulated, during the HSC lymphoid lineage specification.

\section{Fucose-Depleted HSC Exhibit Enhanced Myelopoiesis and Suppressed Lymphopoiesis in Vivo that is Partially Reversed by Activated Notch1 Intracellular Domain}

Although $F X^{-1-}$ mice displayed a twofold decrease in the frequency of LSK cells by immunophenotyping, they revealed a 13.7-fold reduction in HSC frequency by the functional analysis. Thus a 6.8-fold discrepancy of stem cell frequency determined by limiting dilution transplantation and by immunophenotyping suggests a functional defect of fucose-deficient HSC in marrow engraftment or self-renewal. To further assess the effect of fucose deficiency on marrow HSC reconstitution and blood lineage development, we performed competitive repopulating analyses to compare the contribution of wild-type or $\mathrm{FX}^{-1-}$ testing cells (Ly5.2) to that of competing cells (Ly5.1) after transplantation into lethally irradiated wildtype mice (Figure 3A).

The contribution of $F X^{-1-}$ but not wild-type cells (percentage of Ly5.2) was substantially decreased when testing cells were mixed with competing cells at 1:1 and 3:1 ratios (Figure $3 \mathrm{~B}$ ). The contribution of $F X^{-1-}$ cells was almost undetectable when one part of the $F X^{-1-}$ cells was injected with three parts of the competing cells. In comparison, the contribution of wild-type cells injected at the same ratio was present in proportion to the number of the cells injected. Analysis of the bone marrow at 12 weeks after transplanting 1:1 mixture of testing and competing cells revealed that $F X^{-1-}$ LSK cells decreased to about one-third of the wild-type counterparts. Thus, the general decline in numbers observed in the contribution of $\mathrm{FX}^{-1-}$ cells to the bone marrow reflects a depletion of the fucose-deficient HSCs (Figure 3C).

The impact of fucose deficiency on blood lineage distribution was further examined in competitive repopulation assays. We found that $F X^{-1-}$ cells displayed an increased granulocytic but a decreased lymphoid reconstitution, relative to the wild-type control, when $F X^{-1-}$ cells were mixed with wild-type competitors in a ratio of $1: 1$ or $3: 1$ (Figure 3D). These observations indicate that fucosylation-deficient marrow cells have enhanced myeloid but decreased lymphoid developmental potential. The absolute neutrophil numbers were unchanged be- 
A

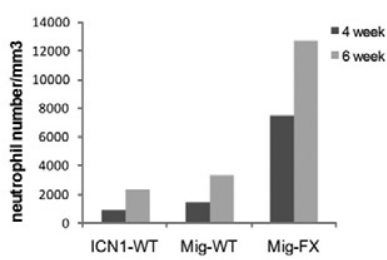

C

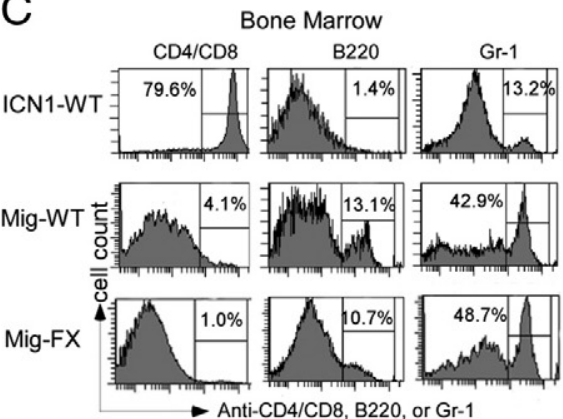

B
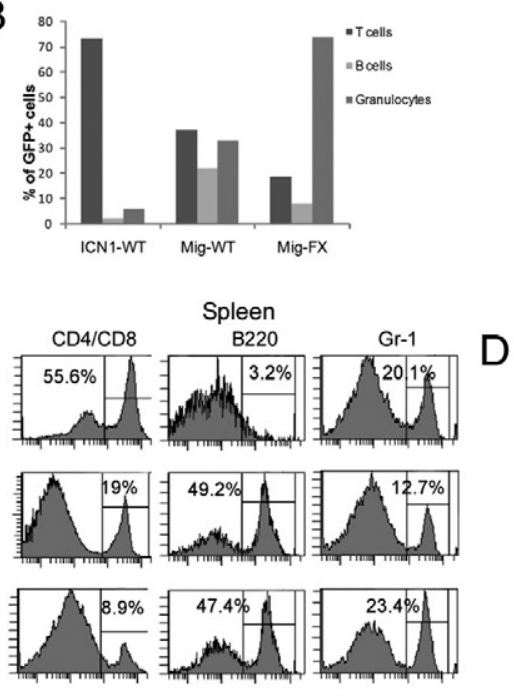

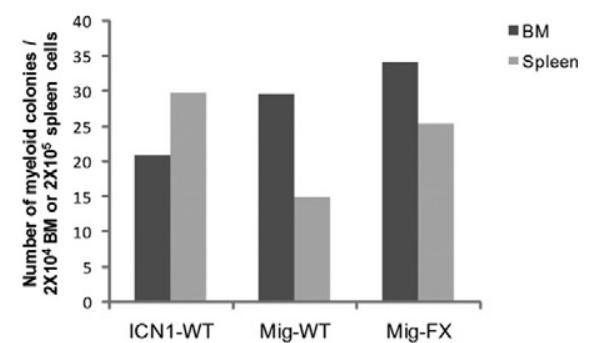

Figure 4. Expression of activated Notch1 (ICN1) partially suppresses the neutrophilia and marrow myeloid expansion induced by the $F X^{\prime-}$ progenitors. A: Analysis of peripheral neutrophils $\left(\mathrm{Gr}_{-} 1^{+}\right)$by FACS in wild-type mice 4 and 6 weeks after receiving syngeneic $F X^{\prime-}$ BM progenitors transduced with ICN1 or Mig vector (ICN1-wild-type, Mig-wild-type), and in $F^{-1-}$ mice receiving $F X^{-1-}$ BM progenitors transduced with Mig vector (Mig- $F X$ ). B: Flow cytometric analysis of peripheral T cells $\left(\mathrm{CD}^{+}\right.$or $\left.\mathrm{CD}^{+}\right)$, B cells $\left(\mathrm{B} 220^{+}\right)$, and granulocytes $\left(\mathrm{Gr}^{+}\right)$in the $\mathrm{GFP}^{+}$populations 6 weeks after transplantation. $\mathbf{C}$ : Flow cytometric analysis of marrow and spleen T cells, B cells, and granulocytes in the $\mathrm{GFP}^{+}$populations six weeks after transplantation. Data shown (A-C) are one representative of two to three mice in each group, with $\mathrm{GFP}^{+}$populations ranging from $5 \%$ to $12 \%$ in all mice groups. D: CFU analysis of marrow or spleen progenitors six weeks after transplantation. Bar graphs indicate average numbers of myeloid colonies (CFU-G, CFU-M, and CFU-GM) per $2 \times 10^{4}$ total marrow nucleated cells, or per $2 \times$ $10^{5}$ splenic cells, from duplicates of two to three mice in each group.

cause of the decreased chimerism established by the $F X^{-1-}$ cells.

To determine whether the aberrant lineage homeostasis developed from $\mathrm{FX}^{-1-}$ marrow cells can be attributed to defective Notch1 signaling activation, we performed bone marrow transplantation where donor $F X^{-1-}$ progenitors were transduced with either constitutively active Notch1-expressing retroviral vectors (ICN1) or vector controls (pMig). Previous studies have shown that expression of activated Notch1 resulted in the development of $\mathrm{T}$ cell leukemia/lymphoma 2 months after transplantation, whereas mice receiving activated Notch1 marrow progenitors 3 weeks after transplantation contained immature $\mathrm{CD}^{+}{ }^{+} \mathrm{CD} 8{ }^{+} \mathrm{T}$ cells while their early $\mathrm{B}$ cells progenitor development was blocked. ${ }^{21,32}$ Here, we found that one month after transplantation, neutrophil counts were not elevated in wild-type recipients receiving ICN1expressing $F X^{-1-}$ progenitors, when compared with the neutrophil numbers in wild-type recipients receiving wildtype marrow progenitors (data not shown). The neutrophil counts, however, were elevated 1.8-fold and 7.5-fold in wild-type and $F X^{-1-}$ recipients receiving $F X^{-1-}$ progenitors transduced with pMig, respectively, when compared with wild-type recipients receiving ICN1 (Figure 4A). Six weeks after transplantation, neutrophils continued to mildly increase in wild-type mice receiving either pMig or ICN1-expressing $F X^{-1-}$ progenitors. In $F X^{-1-}$ recipients that received pMig $F X^{-/-}$progenitors, their netrophil counts remained markedly elevated (Figure 4A). Analysis of peripheral $\mathrm{T}, \mathrm{B}$, and granulocytes in the $\mathrm{GFP}^{+}$cells revealed that, when compared with wild-type mice receiving pMig, wild-type mice receiving ICN1 displayed an increase in frequency of $\mathrm{CD}^{+} \mathrm{CD}^{+} \mathrm{T}$ cells $(73.4 \%$ versus $37.1 \%$ ), and a decrease in frequency of $\mathrm{Gr}-1^{+}$ cells $(6.1 \%$ vs $33 \%)$. $F X^{-1-}$ mice receiving pMig had decreased lymphocytes and drastically elevated granulocytes (Figure 4B). Together, it appears that activated Notch1 partially corrects the mild neutrophilia conferred from the $F X^{-1-}$ progenitors in a wild-type recipient background. The effect of activated Notch1 on the severe neutrophilia contributed by the fucose-deficient stromal environment, however, cannot be assessed as all of the $\mathrm{FX}^{-1-}$ mice receiving ICN1-expressing $\mathrm{FX}^{-1-}$ progenitors did not survive beyond 2 weeks after transplantation. The effect of Notch1 activation in $F X^{-1-}$ progenitors on bone marrow and spleen lineage homeostasis was assessed by flow cytometry, using GFP expression to identify transduced cells. Six weeks after transplantation, the frequency of mature $\mathrm{Gr}^{+}{ }^{+}$granulocytes was $13.2 \%$ of $\mathrm{GFP}^{+}$ cells in the marrow of wild-type recipients receiving ICN1expressing $F^{-1-}$ progenitors, $42.9 \%$ and $48.7 \%$ of $\mathrm{GFP}^{+}$ cells in wild-type and $F X^{-1-}$ recipients receiving pMig, respectively. The frequency of mature granulocytes in the spleen was $20.1 \%, 12.7 \%$, and $23.4 \%$ of $\mathrm{GFP}^{+}$cells in wild-type mice receiving ICN1, wild-type, and $F X^{-1-}$ mice receiving pMig, respectively (Figure $4 \mathrm{C}$ ). The frequencies of mature granulocytes were in the range of $45 \%$ to $63 \%$ of $\mathrm{GFP}^{-}$cells in the marrow of all three groups of mice, with the highest frequency found in $F X^{-1-}$ recipients receiving pMig (data not shown). This observation is consistent with our previous findings of the stromal environment-dependent control of myeloproliferation in FX ${ }^{-1-}$ mice. Similarly, the frequency of $\mathrm{GFP}^{-}$granulocytes in the spleen was in the range of $3.7 \%$ to $10.8 \%$ in all three groups of mice, with the highest frequency found in $F X^{-1-}$ recipients receiving pMig (data not shown). Analysis of marrow and spleen progenitors by methylcellulose culture revealed that single or double myeloid colony num- 
bers were increased in the marrow and the spleen of wild-type mice receiving pMig and were further increased in $\mathrm{FX}^{-1-}$ mice receiving pMig. However, the myeloid colony numbers appeared to be decreased in the marrow and remained unchanged in the spleen of the wild-type mice receiving $F X^{-1-}$ progenitors expressing ICN1 (Figure 4D). Similar to a previous report, ${ }^{31}$ we identified a population of immature $\mathrm{CD} 4^{+} \mathrm{CD} 8^{+} \mathrm{T}$ cells in the marrow and the spleen of wild-type mice receiving ICN1. This phenotype was further accompanied by a block of $B$ cell development (Figure 4C). Considered together, these data suggest that activated Notch1 partially suppressed the expansion of granulocyte derived from the $\mathrm{FX}^{-1-}$ progenitors in the marrow. Moreover, expression of constitutively active Notch1 did not suppress the splenic myeloproliferation induced by fucose-deficiency.

\section{ES Cells Deficient in Notch1 Receptor or Pofut1 Exhibit Suppressed Lymphopoiesis but Enhanced Myelopoiesis in Vitro}

The observations from $\mathrm{FX}^{-1-}$ mice are consistent with the hypothesis that enhanced myelopoiesis and suppressed lymphopoiesis are accounted for by loss of Notch-dependent control on lineage homeostasis as a consequence of loss of Notch O-fucosylation. To confirm this hypothesis, we sought to assess the role played by the O-fucosyltransferase Pofut1 in the control of myelopoiesis and lymphopoiesis because Pofut1 is responsible for adding fucose molecules to consensus EGF repeats on Notch receptors. ${ }^{23,33}$ The embryonic lethal phenotypes of Notch1-null and Pofut1-null mice prohibit the use of their hematopoietic progenitors to study the effect of Notch1 or Pofut1 on myelopoiesis. ${ }^{34-36}$ Instead, to determine whether the aberrant myeloid reconstitution by $F^{-1-}$ cells is attributable specifically to suppressed Notch signaling as a consequence of either loss of Notch1 receptor or loss of O-linked fucose on Notch receptors, we analyzed the blood lineage specification from mouse ESCs carrying either a Notch1-null (Notch1 ${ }^{-1-}$ ) or Pofut1null allele (Pofut $1^{-1-}$ ) using a modified in vitro culture system (Figure 5A). ESCs deficient in Pofut2, which catalyzes the addition of $\mathrm{O}$-linked fucose to thrombospondin type 1 repeats (TSRs) ${ }^{37,38}$ were studied in parallel to confirm that it does not modulate Notch-dependent signaling in hematopoiesis. In this system, ESCs were initially differentiated into CD34 ${ }^{+}$cells in methylcellulose before coculturing with either OP9 cells bearing different Notch ligands or control OP9 cells (Figure 5A). ${ }^{30,39}$

After a 15-day culture with control OP9 cells, wild-type ESC-derived CD34 ${ }^{+}$cells had differentiated into myeloid cells expressing Gr-1 (Figure 5B) and B lymphoid cells (data not shown). In contrast, these cells differentiated into DP/CD8 + T lymphocytes (69.3\%, 73.4\%, and 70.9\%, respectively) when cocultured with OP9s bearing Jagged2, Dll1, or Dll4. The induction of T Iymphopoiesis by the Notch ligand-expressing OP9 is consistent with previously published observations of marrow LSK cell differentiation. ${ }^{30}$ The development of mature $T$ cells in culture correlates with the up-regulation of Notch-specific transcripts, including Hes1 and Deltex1 (Figure 5C). Wild-type ESC-derived progenitor cells also displayed efficient Notch ligand (D\|1 and D\|l4) binding (Figure 5D). When CD34 ${ }^{+}$Pofut2 $^{-1-}$ progenitors were cultured under similar conditions, they showed comparable T Iymphopoiesis to wild-type cells. These cells also exhibited similar levels of Notch activation and Notch ligand binding as observed in wild-type ESCs (Figure 5, B-D). Together, these latter observations indicate that Notch activation and its role in inducing $\mathrm{T}$ lymphoid development proceeds normally in the absence of O-fucosylation of TSR-1 repeats.

Although Notch $1^{-1-}$ ESCs displayed a normal myeloid and $B$ lymphoid differentiation pattern when cultured on OP9-controls, they failed to generate $T$ Iymphocytes on Notch ligand-expressing OP9s. Instead, these cultures contained a robust population of myeloid cells, which accounted for between $39.4 \%$ and $45.3 \%$ of the total hematopoietic cells in the culture (Figure 5B). The absence of $\mathrm{T}$ lymphopoiesis in these cultures correlated with the basal levels of Hes 1 and Deltex 1 expression and the background level of Notch ligand binding, all of which indicate complete abrogation of Notch activation (Figure 5, B-D). Regardless of whether Notch ligand was present in the culture, when Pofut1 ${ }^{-1-}$ ESCs were assayed, they generated a pattern of increased myelopoiesis and absence of T lymphopoiesis that was essentially identical to that of Notch $1^{-1-}$ ESCs. In contrast to the complete abrogation of Notch activation and loss of Notch ligand binding observed in Notch $1^{-1-}$ ESCs, we found that the expression of Notch-targeted transcripts was diminished (but not absent) whereas Notch ligand binding was markedly decreased (but not absent), relative to wild-type cells (Figure 5, B-D). These observations indicate that the partial suppression of Notch activation in the absence of O-linked fucosylation on Notch yields an ESC hematopoietic phenotype similar to that observed in Notch $1^{-1-}$ cells. Further analysis of these ESCs revealed that the surface expression of Notch1 was absent in Notch1 ${ }^{-1-}$ HPCs but mildly decreased in Pofut1 ${ }^{-1-}$ HPCs. The expression levels of other Notch receptors (Notch2, Notch3, and Notch4) in Pofut1 ${ }^{-1-}$ HPCs were not up-regulated when compared with the expression of these receptors in Notch $1^{-1-}$ cells (see Supplemental Figure S1 at http:// ajp.amjpathol.org). Together, these findings suggest that a defective Notch-ligand binding mediated by Notch1 could be the primary cause for the phenotype seen in Pofut $^{-1-}$ cells.

\section{Aberrant in Vivo Hematopoiesis from ES Cells Deficient in Notch1 Receptor or Notch O-Fucose Modification}

To confirm that the anomalous in vitro lineage developmental potential of Notch1 $1^{-1-}$ and Pofut1 ${ }^{-1-}$ ESCs is reflective of their in vivo features, we performed intrafemoral transplantation of ESC-derived CD34 ${ }^{+}$, Ly5 $5.2^{+}$hematopoietic progenitors (HPCs) into nonlethally irradiated recipient mice $\left(\right.$ Ly $\left.5.1^{+}\right)$. ESCs were first differentiated into hematopoietic progenitors in methylcellulous me- 
A
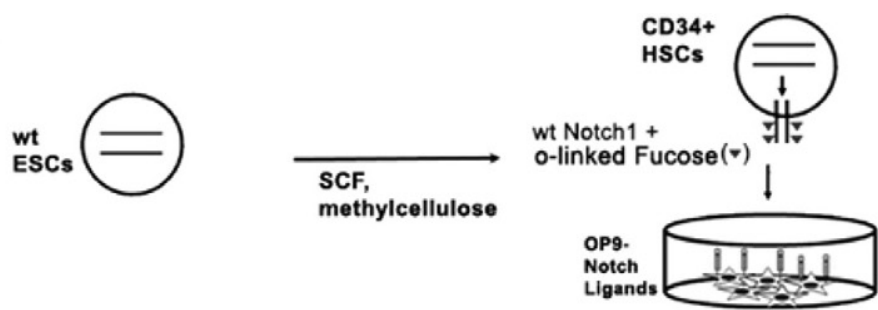

(T)

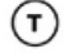

IL-7, FIt3-L

(T)

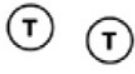

DPICD8* T
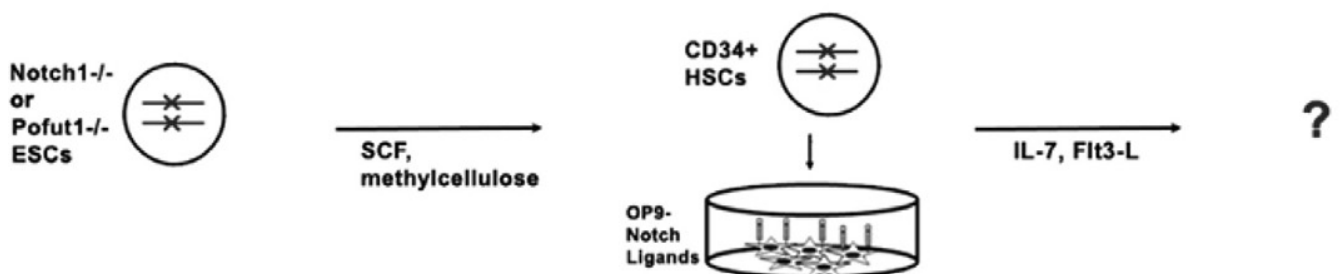

B

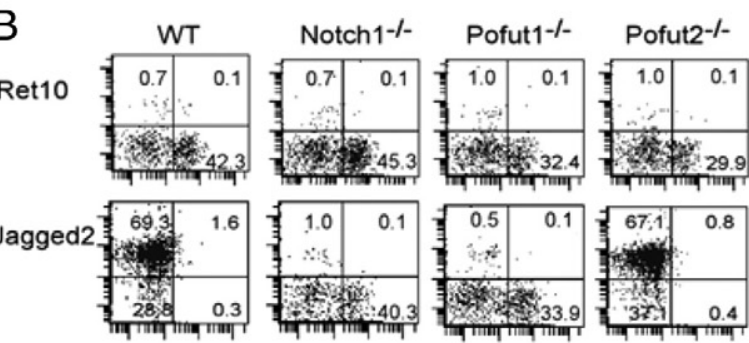

C

DII1
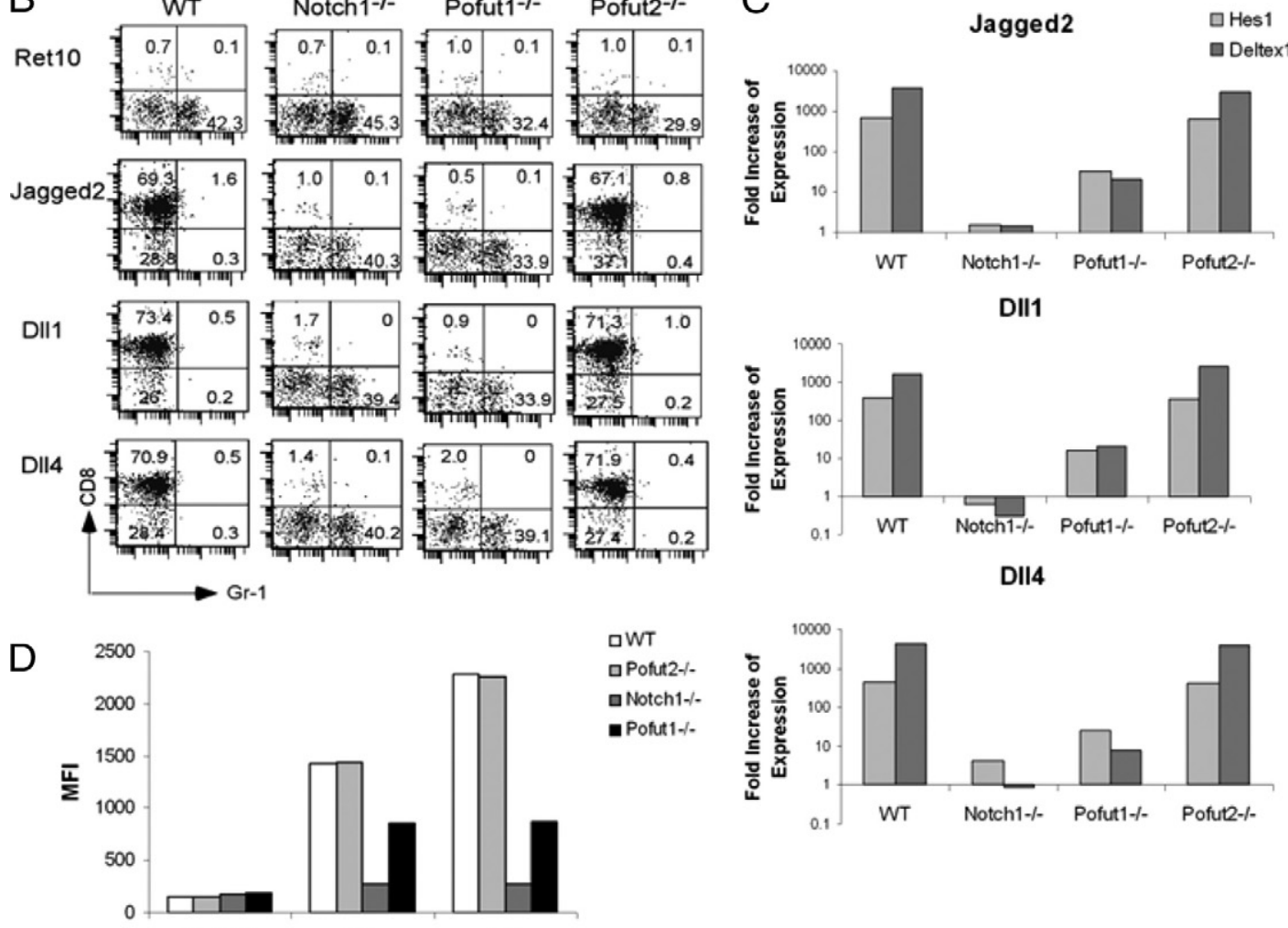

aWT

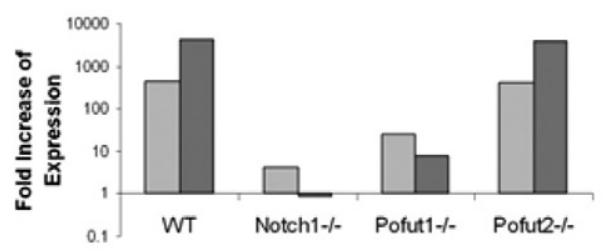

higG FC

aPofut $2-$

a Notch1 $1-$

- Pofut $1 \%$

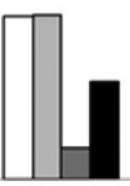

DII1

Figure 5. Notch $1^{-/-}$or Pofut $1^{-/-}$ESCs have suppressed lymphopoiesis but enhanced myelopoiesis in vitro. A: Schematic representation of the in vitro coculture of ESCs (wild-type, Notch $1^{-\prime-}$, Pofut $1^{-/-}$, and Pofut $2^{-\prime-}$ ) with OP9 cells expressing Notch ligands in the presence of IL7 and Flt3 ligand. B: FACS analysis of CD8 and Gr-1 expression on four lines of ESC-derived hematopoietic cells after coculture with control OP9 (Ret10) or OP9 expressing Jagged2, Dll1, or Dll4. C: Expression of Hes1 and Deltex1 was analyzed by quantitative RT-PCR on ESC-derived hematopoietic cells relative to the levels detected in OP9-Ret10 (set at 1). Data shown are one representative of three similar experiments. D: One representative flow cytometry analysis of binding of recombinant Notch ligands Dll1, Dll4, and control (human IgG1 Fc) to ESC-derived hematopoietic cells. Bar graph indicates MFI.

dium (Figure 6A). The percentage of CD34 ${ }^{+}$HPCs in these differentiated ESCs is consistent with other reports ranging from 8 to $14 \%{ }^{17}$

The earliest hematopoietic reconstitution from ESCderived HPCs was observed 2 weeks after the injection of CD34 ${ }^{+}$cells. By 12 weeks, the proportion of ESC-derived Ly $5.2^{+}$cells in the peripheral blood ranged from $52 \pm$ $25 \%$ to $79 \pm 13 \%$ for all types of cells transplanted. The fraction of Ly5.2+ $2^{+}$cells remained steady through 16 to 20 weeks after transplantation. Flow cytometric analysis of peripheral blood revealed that the population of wild-type HPC-derived T cells, B cells, and granulocytes comprising $25.1 \pm 8.4 \%, 54.1 \pm 9.2 \%$, and $12.3 \pm 1.4 \%$, Ly5.2 $2^{+}$ cells, respectively. A similar lineage distribution was found in mice transplanted with Pofut2 ${ }^{-1-}$ HPCs (Figure $6, B$ and $C$ ). At 12 weeks, mature $T$ and B cells derived from Notch1 ${ }^{-1-}$ HPCs represented only $8.8 \pm 2.5 \%$ and $16.9 \pm 3.3 \%$ of the transplanted cells, respectively. In 
A<smiles>[CH2][C@@H]1CC=CCC1</smiles>

B
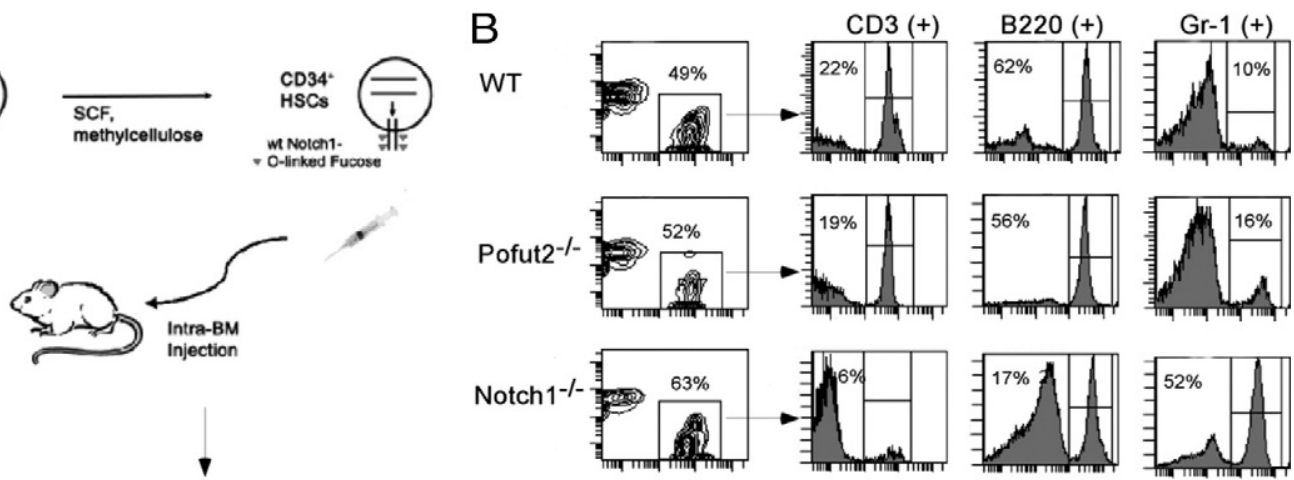

Peripheral blood analysis
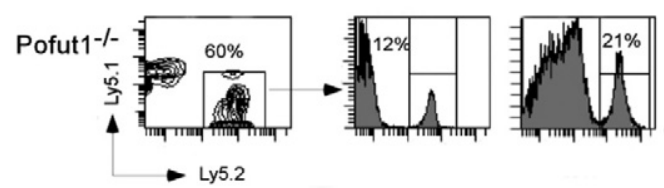
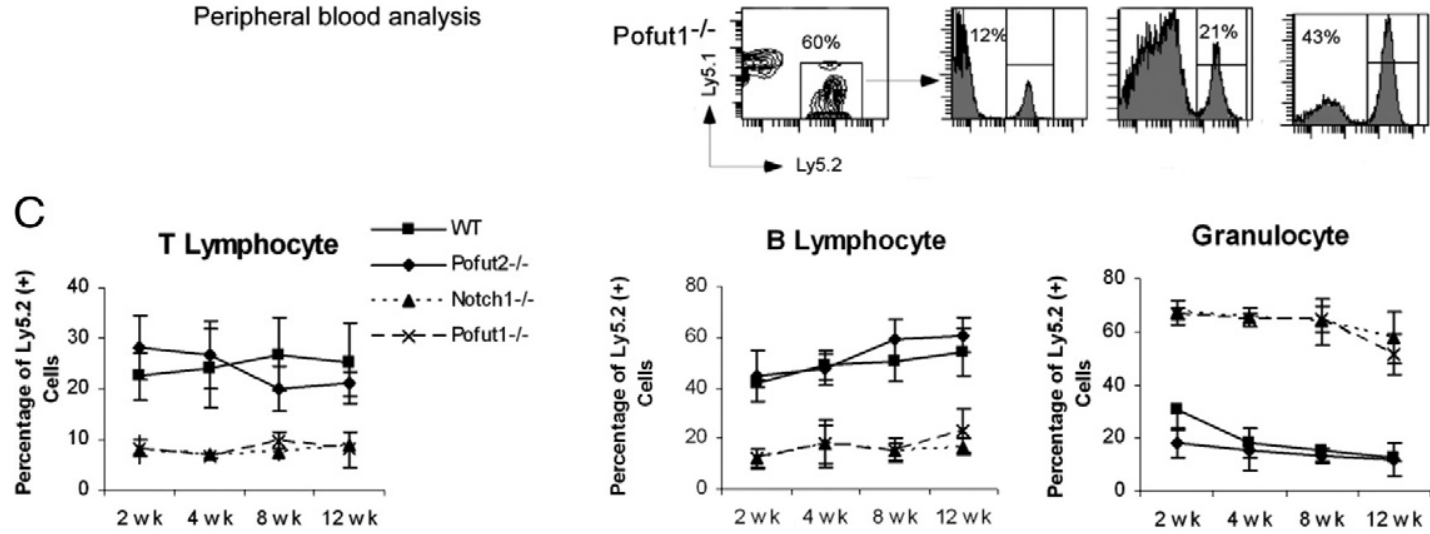

B Lymphocyte

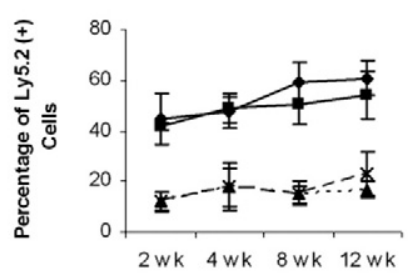

Granulocyte

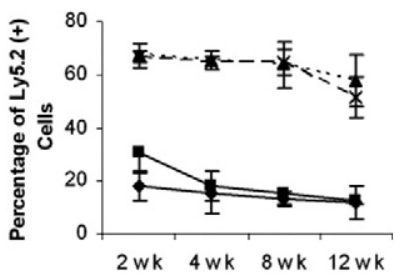

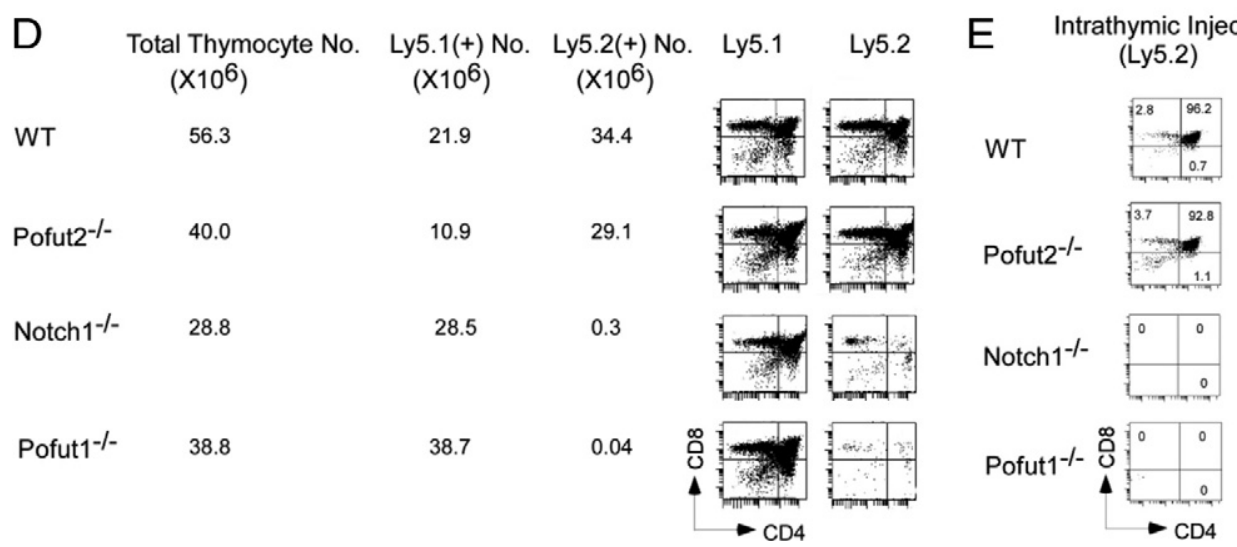

Figure 6. Notch $^{-1-}$ or Pofut $1^{-1-}$ HPCs have aberrant in vivo hematopoiesis. A: Schematic representation of HPC intrafemoral injection and in vivo hematopoietic reconstitution in recipient mice. B: FACS analysis of peripheral blood reconstitution by antibodies against T cells (CD3), B cells (B220), and neutrophils (Gr-1) after gating on ESC-derived cells (Ly5.2). C: Line graphs of peripheral blood lymphoid and myeloid lineage reconstitution by ESC-derived cells (Ly 5.2) at 2, 4, 8, and 12 weeks after intrafemoral transplantation. D: Comparison of total thymocyte numbers and the numbers of thymocytes contributed by the host (Ly5.1) and HPCs (Ly5.2). FACS analysis was performed with anti-CD4 and anti-CD8 after gating on Ly5.2 or Ly5.1 cells. Data shown are one representative of three similar experiments. E: Thymocyte development after intrathymic transplantation of HPCs (Ly5.2) into FX ${ }^{/-}$mice (Ly5.1) maintained on standard chow. Data shown are one representative of three similar experiments.

comparison, the proportion of the granulocytes from Notch $1^{-1-}$ HPCs reached $57.7 \pm 9.6 \%$. The hematopoietic reconstitution of the Pofut1 ${ }^{-1-}$ HPC donor had a pattern of lineage distribution similar to that of Notch $1^{-1-}$ HPC-reconstituted mice: decreased $T$ and B lymphoid compartments, increased granulocytic chimerism (Figure 6, B and C) and absolute neutrophilia (see Supplemental Table 1 at http://ajp.amjpathol.org). As summarized in Table 2, 12 weeks after transplantation, hematopoietic reconstitution by Pofut2 ${ }^{-1-}$ HPCs resulted in a lineage distribution that was essentially identical to mice reconstituted with wild-type HPCs. In contrast, Notch1 ${ }^{-1-}$ and Pofut $^{-1-}$ HPCs yielded a lymphoid-suppressed but myeloid-expanded phenotype. The absolute number of $B$ cells derived from donors carrying Notch1-1- or Pofut $^{-1-}$ alleles remained similar because of increased WBC numbers (see Supplemental Table 1 at http://ajp. amjpathol.org). The proportion and absolute numbers of $\mathrm{T}$ cells, B cells, and granulocytes generated from hosts $\left(\right.$ Ly5 $\left.51^{+}\right)$were similar among mice receiving all four ESC lines, suggesting that the lymphoid-suppressive and myeloid-enhancing phenotype in recipients transplanted with either Notch $1^{-1-}$ or Pofut 1 ${ }^{-1-}$ HPC is cell-autonomous.

A decreased $T$ Iymphocyte population in the periphery of recipients receiving Notch $1^{-1-}$ or Pofut $1^{-1-}$ HPCs is a result of suppressed thymic $T$ lymphopoiesis in these 
Table 2. Lineage Distributions of ESC-Derived Ly5.2 and Host-Derived Ly5.1 Cells in Nonlethally Irradiated Recipient Mice Transplanted with CD34 ${ }^{+}$ESC-HPCs (12 Weeks after Injection)

\begin{tabular}{|c|c|c|c|c|c|c|}
\hline & \multicolumn{6}{|c|}{ Peripheral blood } \\
\hline & \multicolumn{3}{|c|}{ Ly5.2+ Cells $(n=4)$} & \multicolumn{3}{|c|}{ Ly5.1+ Cells $(n=4)$} \\
\hline & $\mathrm{T}(\%)$ & $\mathrm{B}(\%)$ & $\mathrm{G}(\%)$ & $\mathrm{T}(\%)$ & $\mathrm{B}(\%)$ & $\mathrm{G}(\%)$ \\
\hline Wild-type & $25.1 \pm 8.4$ & $54.1 \pm 9.2$ & $12.3 \pm 1.4$ & $44.8 \pm 9.8$ & $25.2 \pm 9.4$ & $16.7 \pm 7.0$ \\
\hline Pofut2 ${ }^{-/-}$ & $21.0 \pm 2.5$ & $60.9 \pm 6.6$ & $11.6 \pm 6.2$ & $43.5 \pm 6.5$ & $24.4 \pm 10.6$ & $23.0 \pm 12.5$ \\
\hline Notch $1^{-1-}$ & $8.8 \pm 2.5^{\star *}$ & $16.9 \pm 3.2^{*}$ & $57.7 \pm 9.6^{\star *}$ & $32.3 \pm 2.0$ & $34.3 \pm 3.9$ & $23.8 \pm 1.5$ \\
\hline Pofut1 ${ }^{-1-}$ & $8.0 \pm 3.4^{\star *}$ & $23.3 \pm 8.6^{*}$ & $51.6 \pm 7.6^{\star *}$ & $36.7 \pm 9.4$ & $30.5 \pm 6.8$ & $17.2 \pm 7.2$ \\
\hline
\end{tabular}

${ }^{*} P<0.01 ;{ }^{*} P<0.0001$

mice. In one representative experiment, the absolute cell count of the donor-derived thymocytes (Ly5.2 ${ }^{+}$) were only $0.3 \times 10^{6}$ and $0.04 \times 10^{6}$ in each mouse receiving Notch $1^{-1-}$ or Pofut $1^{-1-}$ HPCs, respectively, whereas the donor thymocyte numbers in each mouse receiving wildtype or Pofut2 ${ }^{-1-}$ HPCs were $34.4 \times 10^{6}$ and $29.1 \times 10^{6}$, respectively. Both single positive $(\mathrm{SP})$ and double positive (DP) T cells derived from either Notch $1^{-1-}$ or Pofut $1^{-1-}$ HPCs were significantly decreased (Figure 6D). In comparison, the development of mature thymocytes generated from the hosts $\left(\right.$ Ly5. $\left.1^{+}\right)$was not disturbed. To exclude the possibility that defective thymopoiesis is attributable to a thymus-homing defect of HPCs, CD34 ${ }^{+}$cells were directly injected into the thymus of fucose-depleted $\mathrm{FX}^{-/-}$mice (Ly5.1) whose ability to support the host thymocyte development is retarded (unpublished data). Essentially no SP or DP mature T cells were found derived from the injected Notch $1^{-1-}$ or Pofut $1^{-1-}$ HPCs, whereas robust T cells were identified from wild-type and Pofut2 ${ }^{-1-}$ HPCs (Figure 6E).

The increase in granulocytes in mice receiving Notch $1^{-1-}$ or Pofut1 ${ }^{-1-}$ HPCs was accompanied by marrow myeloproliferation and extramedullary hematopoiesis. The spleens of these mice were mildly enlarged, of which the red pulps were expanded because of myeloid hyperplasia (see Supplemental Fig S2, A and B at http:// ajp.amjpathol.org). The B lymphocyte progenitors were mildly decreased but did not display any obvious developmental blockade in the marrow (data not shown). There is a decrease of $\operatorname{lgM}^{\text {hi }} \operatorname{lgD}^{\text {lo }} \mathrm{B}$ cells in spleens of mice receiving Pofut1 ${ }^{-1-}$ HPCs, as was found in $\mathrm{FX}^{-1-}$ mice spleens (Figure 7). The splenic $\operatorname{lgM}^{\text {hi }} \lg D^{\text {lo }} \mathrm{B}$ cells comprise type1 transitional (T1) and marginal zone $B$ cells (MZB), which are decreased in Notch2 conditional

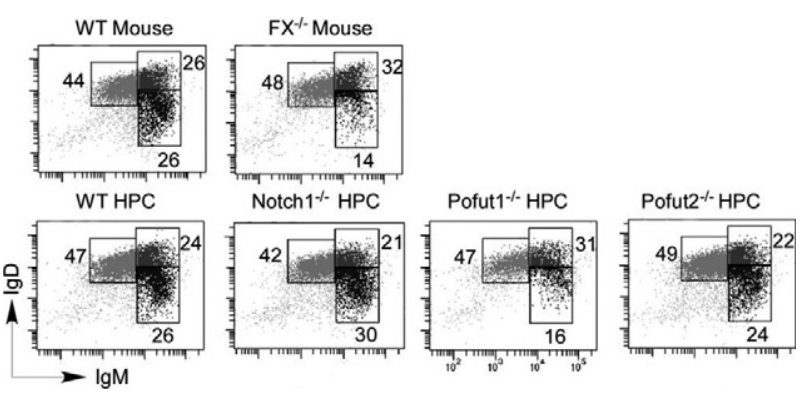

Figure 7. A Decreased MZB cell compartment in the spleens of $\mathrm{FX}^{-1-}$ mice and mice receiving Pofut $1^{-1-}$ HPCs. A representative FACS analysis of T1 B cells and MZB cells (IgM ${ }^{\text {hi }} \operatorname{IgD}{ }^{\text {lo }}$ ) in the spleens of wild-type and $F X^{/-}$mice (top; $n=4$ ) and mice receiving ES-derived HPCs (bottom; $n=4$ ). The numbers denote the percentage of cells in the indicated squares. knock-out mice. ${ }^{40}$ Mice receiving either Notch $1^{-1-}$ or Pofut $^{-1-}$ HPCs also displayed infiltrations of neutrophils and myeloid progenitors to the peripheral organs such as lymph nodes (see Supplemental Fig S2C at http://ajp. amjpathol.org). However, these mice displayed a normal peripheral blood platelet count (see Supplemental Fig S3 at http://ajp.amjpathol.org). These findings further support that loss of Notch1 or Notch O-fucosylation leads to chronic granulomonocytic proliferation.

\section{Discussion}

In this study, we identified a role of Notch receptor O-fucose modification in regulating blood lineage homeostasis. We confirmed our previous findings that a myeloproliferation in mice with fucosylation deficiency is attributable to an enhanced myeloid developmental potential of HSCs. The data presented in our current study indicate that Notch activation modulates lineage commitment and development from HSCs. This regulation exerted by Notch is controlled by $\mathrm{O}$-fucosylation of Notch receptors. We identified that the absence of O-fucose on Notch receptors results in decreased lymphoid priming but enhanced myeloid potential. This phenotype is accompanied by suppressed Notch ligand binding and Notch signaling activation in HSCs.

Commitment of HSCs to either a myeloid or lymphoid lineage is believed to be regulated by the activation of several key transcription factors, which establish the profile of genes characteristic of that lineage. ${ }^{29}$ The tyrosine kinase receptor Flt3 and the transmembrane protein Notch1 receptor are important proteins for lymphoid lineage initiation, ${ }^{41,42}$ whereas PU. 1 and $\mathrm{C} / \mathrm{EBP} \alpha$ are transcription factors that control myeloid lineage development. ${ }^{43}$ It is known, and confirmed by our observations in this study, that Notch1 promotes T Iymphoid commitment by stimulating $T$ cell-specific transcription factors while down-regulating myeloid transcription factors. ${ }^{29,44}$ We identified an enhanced myeloid but a suppressed lymphoid potential of HSCs in the absence of fucose. This was demonstrated that fucose-deficient HSCs form more myeloid progenitor colonies and MPPs form $F X^{-1-}$ mice failed to respond to Notch ligand-induced $T$ lineage commitment while exhibiting a sustained expression of myeloid transcriptional activity in vitro. The suppressed lymphoid potential of fucose-deficient hematopoietic progenitors is also suggested by the reduction of Flt3 tran- 
scripts in lymphoid-primed MPPs. It remains unclear why the expression of myeloid transcription factors found in fucose-deficient progenitors in response to Notch ligand stimulation is increased. We speculate that weak Notch activation may promote myeloid-specific events in fucose-deficient progenitors. In comparison, strong Notch signaling may promote the elevation of lymphoid transcription factors as seen in wild-type or fucose-repleted cells. Alternatively, altered Notch signaling pathways attributable to O-fucosylation deficiency, such as misfolding of Notch receptors in the ER, ${ }^{22}$ decreased Notch receptor or Notch ligand endocytosis, ${ }^{45,46}$ may cause enhanced myeloid commitment from MPPs through unidentified molecular mechanisms.

Our data from in vitro hematopoietic differentiation of ESC is consistent with the hypothesis that Notch activation supports T lymphopoiesis and inhibits myelopoiesis. Consistent with this finding, we observed that a transient and balanced leukocyte lineage development established by wild-type ESCs, whereas loss of Notch1 results in a diminished lymphoid but enhanced myeloid lineage outcome. We also observed that the balanced lymphoid versus myeloid lineage outcome exerted by Notch activation is controlled by the modification of $\mathrm{O}$-fucose on Notch. Both in vitro and in vivo hematopoiesis generated by ESCs display enhanced myeloid but inhibited lymphoid development in the absence of Pofut1. Indeed, mice reconstituted with Notch $1^{-1-}$ or Pofut $1^{-1-}$ progenitors displayed both neutrophilia and myelohyperplasia. This finding is consistent with the myeloproliferation observed in the $\mathrm{FX}^{-1-}$ mice and the enhanced granulopoietic reconstitution produced by fucose-deficient progenitor cells in wild-type recipients. Furthermore, both myeloproliferation and suppression of $\mathrm{T}$ lymphopoiesis are observed in conditional Pofut1 knock-out mice (manuscript in preparation), suggesting that the myeloproliferative phenotype observed in $F X^{-1-}$ mice can be largely attributed to an abnormal Notch signaling control of myelopoiesis in the absence of O-linked fucose on Notch receptors. These findings strongly support the hypothesis that Notch signaling is essential for blood lineage homeostasis by promoting lymphoid development while suppressing overt myelopoiesis. Further studies at the single HSC level are required to define whether such control mechanism is exerted by Notch at the earliest diversification of lymphoid and myeloid progenitor during HSC lineage commitment. Because we have shown that this control mechanism exerted by Notch is dependent on the O-fucose modification of Notch EGF repeats, future studies will examine how each informative EGF-like repeat domain regulates the activity of Notch signaling.

O-fucose moieties are found on other proteins that have EGF-like repeat motifs, including Cripto and coagulation factors, ${ }^{47-50}$ as well as on proteins containing TSR repeat domains. ${ }^{51,52}$ Unlike Pofut1, which is responsible for the addition of fucose to EGF-like repeats, Pofut2 modifies TSR repeats, which was first described in thrombospondin-1. ${ }^{53}$ Our findings of normal blood lineage development using Pofut2 ${ }^{-1-}$ ESC, both in vitro and in vivo, indicate that Pofut2 is not essential for the development of hematopoietic cells. In contrast, Pofut1 is required for blood lineage homeostasis as its deficiency results in enhanced granulocytic potential and suppressed lymphoid potential. This effect is likely caused by decreased binding of Pofut1 ${ }^{-1-}$ ESC-derived hematopoietic cells with Notch ligand. The faulty ligand-receptor interaction crippled the ability of hematopoietic progenitors to transcribe Notch-specific targets. This reduced ligand-receptor binding phenotype may also stem from the decreased cell surface expression of Notch1 in Pofut $1^{-1-}$ HPCs. Interestingly, the cell surface expressions of Notch2, Notch3, and Notch4 are not changed in Pofut $1^{-1-}$-HPCs when compared with that in Notch $1^{-1-}$ HPCs. This is consistent with the observations made by Stahl et al, which indicate that Pofut ${ }^{-1-}$ ES cells exhibit suppressed Notch signaling using a reporter assay. ${ }^{54}$ Although Pofut1 also transfers fucose molecules to EGF repeat domains of Cripto, a coreceptor for Nodal, it is unlikely that the phenotype observed with Pofut ${ }^{-1-}$ ESC is caused by a faulty Nodal-mediated signaling as it has been shown that Nodal signaling is not disturbed in Pofut $1^{-1-}$ ESCs. ${ }^{55}$ Further, the normal blood lineage distribution established by wild-type host cells in chimeric mice receiving Pofut $1^{-1-}$ progenitors argues against that secreted plasma proteins, such as coagulation factors derived from $\mathrm{PO}_{\mathrm{O}}$ fut $1^{-1-}$ ESCs, may contribute to the aberrant phenotypes observed.

All four Notch receptors are expressed in HSCs, each of which has consensus sequences known to be modified by O-fucose. ${ }^{56}$ The similarity of aberrant hematopoietic reconstitution between Notch $1^{-1-}$ and Pofut $1^{-1-}$ progenitors suggests that among the members of the Notch family, Notch1 probably plays the primary role in blood lineage maintenance. This notion is supported by the findings that the expression of a constitutively activated Notch1 partially suppressed myeloproliferation conferred by the $F X^{-1-}$ marrow progenitors. However, we cannot exclude the possibility that the suppression of myeloproliferation in the marrow is only secondary to the expansion of immature $T$ cells induced by activated Notch1. In contrast, Notch1 activation seems to play no role in splenic myelohyperplasia induced by fucose deficiency, suggesting that defective signaling of other Notch receptors may play a more important role in extramedullary myeloproliferation. Our observation that Notch1 deficiency leads to an enhanced myelopoiesis and suppressed T lymphopoiesis, however, differs from the findings by Radtke et al who previously demonstrated that conditional inactivation of Notch1 arrested T cell development whereas the differentiations of other lineages are unaffected. ${ }^{9}$ The discrepancy of these observations suggests that other Notch receptors may have redundant functions in myelopoietic suppression but not in ES-derived hematopoiesis in mice. Alternatively, an enhanced myeloid reconstitution by Notch $1^{-1-}$ progenitors may reflect a developmental stage-specific effect of ES-derived progenitors on hematopoietic tissues, whereas such an effect is diminished or bypassed in Cre-LoxP inactivation system that targets the adult hematopoietic tissues and cells. Our findings of the suppressed T lymphopoiesis and the enhanced myelopoiesis with a rather normal peripheral $\mathrm{B}$ lymphoid compartment in $F X^{-1-}$ mice and the in 
vivo reconstitution of ESC may suggest a role of Notch signaling at the common progenitor of $\mathrm{T} /$ myeloid branching point, as recently demonstrated by Bell et al that early thymic progenitors possess T and myeloid potentials. ${ }^{57} \mathrm{Al}-$ ternatively, a rather normal $\mathrm{B}$ lymphoid compartment may reflect a combined effect of Notch signaling at two branching points (i.e., suppressed Notch activation decreases CLP numbers at the CLP versus CMP restriction while increasing $B$ lymphocyte development at the expense of $T$ lymphocytes at the T/B restriction). Despite a normal B cell compartment in the periphery, we observed a decrease of $\mathrm{T} 1 \mathrm{~B}$ cells and MZB cells in $\mathrm{FX}^{-1-}$ mice and mice reconstituted with Pofut $1^{-1-}$ HPCs. This finding suggests a role of fucose-dependent Notch2 signaling in MZB cell development. In contrast to the recent report that Notch signaling promotes megakaryocyte development, ${ }^{58}$ we did not observe a significant reduction of platelet counts in $\mathrm{FX}^{-1-}$ mice or in mice receiving Notch $1^{-1-}$ or Pofut $1^{-1-}$ HPCs, suggesting O-fucose modification of Notch is not essential for megakaryocytopoiesis.

$F X^{-1-}$ mice display a mild decreased concentration of LSKs under steady state. These mice have a profound decrease of HSC frequency and an aberrant repopulating function after myeloablative transplantation. The less competitive repopulating ability of fucose-deficient HSCs cannot be fully explained by an approximately twofold dilutional effect on the stem cell compartment attributable to myeloproliferation. It is, however, accompanied by a diminished HSC compartment in recipients of these cells after transplantation, which is likely attributable to the increased differentiation of HSC toward myeloid lineage. ${ }^{15}$ Alternatively, this observation is also possibly attributable to an defective stem cell engraftment or reduced HSC self-renewal, as demonstrated by a decreased stem cell frequency in the limiting dilution assay. Suppressed Notch activation in fucose-depleted LSKs, however, may not be relevant to the observed changes in the HSC compartment of $F X^{-1-}$ mice, as suggested by a recent report that HSC self-renewal is not affected by a dominant negative inhibitor of canonical Notch signaling pathway. ${ }^{11}$ In fact, we found that the expression of activated Notch1 is associated with a decrease of the LSK population (data not shown). Whether such aberrancies in HSC function observed in $\mathrm{FX}^{-1-}$ mice reflects an anomaly in Notch pathways upstream of Notch intracellular signaling (e.g., the interaction between Notch-expressing HSCs with the ligand-expressing osteoblasts, which dictates the physical association of HSC with marrow microenvironment that is critical for HSC biology) is unclear. ${ }^{46}$ Further, other secreted or membrane-associated fucosylated stromal components may also work in concert with Notch directly, or indirectly, to maintain HSC function. In fact, only relatively enhanced myeloid potential is developed from fucose-deficient progenitors in a wild-type environment, whereas an absolute neutrophilia is induced by Notch $1^{-1-}$ and Pofut $1^{-1-}$ HPCs, which is likely caused by an altered microenvironment created by Notch $1^{-1-}$ and Pofut $1^{-1-}$ ES-derived cells. Combined with the finding that a more severe myeloproliferative phenotype can be induced by $\mathrm{FX}^{-1-}$ progenitors only in the $F X^{-1-}$ marrow, our study suggests that fucose-defi- cient marrow environment potentiates myeloproliferation induced by fucose-deficient marrow cells. Together these observations support the notion that marrow stem cell niche is maintained by complex interaction of HSCs with stromal cells and signaling molecules in a specialized microenvironment. ${ }^{59,60}$

\section{Acknowledgments}

We thank Justine Ralston and David Lepage for technical support in generating Pofut2 ${ }^{-1-}$ ES cells. We thank Kevin Bunting for insightful discussion of the manuscript.

\section{References}

1. Radtke F, Wilson A, Mancini SJ, MacDonald HR: Notch regulation of Iymphocyte development and function. Nat Immunol 2004, 5:247-253

2. Maillard I, Fang T, Pear WS: Regulation of Iymphoid development, differentiation, and function by the Notch pathway. Annu Rev Immunol 2005, 23:945-974

3. Chiba S: Notch signaling in stem cell systems. Stem Cells 2006, 24:2437-2447

4. Stier S, Cheng T, Dombkowski D, Carlesso N, Scadden DT: Notch1 activation increases hematopoietic stem cell self-renewal in vivo and favors lymphoid over myeloid lineage outcome. Blood 2002, 99:2369-2378

5. Varnum-Finney B, Xu L, Brashem-Stein C, Nourigat C, Flowers D Bakkour S, Pear WS, Bernstein ID: Pluripotent, cytokine-dependent, hematopoietic stem cells are immortalized by constitutive Notch1 signaling. Nat Med 2000, 6:1278-1281

6. Carlesso N, Aster JC, Sklar J, Scadden DT: Notch1-induced delay of human hematopoietic progenitor cell differentiation is associated with altered cell cycle kinetics. Blood 1999, 93:838-848

7. Ohishi K, Varnum-Finney B, Bernstein ID: Delta-1 enhances marrow and thymus repopulating ability of human CD34(+)CD38(-) cord blood cells. J Clin Invest 2002, 110:1165-1174

8. Calvi LM, Adams GB, Weibrecht KW, Weber JM, Olson DP, Knight MC Martin RP, Schipani E, Divieti P, Bringhurst FR, Milner LA, Kronenberg $\mathrm{HM}$, Scadden DT: Osteoblastic cells regulate the haematopoietic stem cell niche. Nature 2003, 425:841-846

9. Radtke F, Wilson A, Stark G, Bauer M, van Meerwijk J, MacDonald $\mathrm{HR}$, Aguet M: Deficient $T$ cell fate specification in mice with an induced inactivation of Notch1. Immunity 1999, 10:547-558

10. Mancini SJ, Mantei N, Dumortier A, Suter U, MacDonald HR, Radtke F: Jagged1-dependent Notch signaling is dispensable for hematopoietic stem cell self-renewal and differentiation. Blood 2005, 105:2340-2342

11. Maillard I, Koch U, Dumortier A, Shestova O, Xu L, Sai H, Pross SE, Aster JC, Bhandoola A, Radtke F, Pear WS: Canonical notch signaling is dispensable for the maintenance of adult hematopoietic stem cells. Cell Stem Cell 2008, 2:356-366

12. Koch U, Lacombe TA, Holland D, Bowman JL, Cohen BL, Egan SE, Guidos CJ: Subversion of the T/B lineage decision in the thymus by lunatic fringe-mediated inhibition of Notch-1. Immunity 2001 15:225-236

13. Koch U, Yuan JS, Harper JA, Guidos CJ: Fine-tuning Notch1 activation by endocytosis and glycosylation. Semin Immunol 2003, 15:99-106

14. Visan I, Tan JB, Yuan JS, Harper JA, Koch U, Guidos CJ: Regulation of T lymphopoiesis by Notch1 and Lunatic fringe-mediated competition for intrathymic niches. Nat Immunol 2006, 7:634-643

15. Zhou L, Li LW, Yan Q, Petryniak B, Man Y, Su C, Shim J, Chervin S, Lowe JB: Notch-dependent control of myelopoiesis is regulated by fucosylation. Blood 2008, 112:308-319

16. Smith PL, Myers JT, Rogers CE, Zhou L, Petryniak B, Becker DJ, Homeister JW, Lowe JB: Conditional control of selectin ligand expression and global fucosylation events in mice with a targeted mutation at the FX locus. J Cell Biol 2002, 158:801-815

17. Zou GM, Wu W, Chen J, Rowley JD: Duplexes of 21-nucleotide RNAs mediate RNA interference in differentiated mouse ES cells. Biol Cell 2003, 95:365-371 
18. de Pooter RF, Schmitt TM, de la Pompa JL, Fujiwara Y, Orkin SH, Zuniga-Pflucker JC: Notch signaling requires GATA-2 to inhibit myelopoiesis from embryonic stem cells and primary hemopoietic progenitors. J Immunol 2006, 176:5267-5275

19. Kushida T, Inaba M, Hisha H, Ichioka N, Esumi T, Ogawa R, lida H, Ikehara S: Intra-bone marrow injection of allogeneic bone marrow cells: a powerful new strategy for treatment of intractable autoimmune diseases in MRL/lpr mice. Blood 2001, 97:3292-3299

20. Heinzel K, Benz C, Martins VC, Haidl ID, Bleul CC: Bone marrow-derived hemopoietic precursors commit to the T cell lineage only after arrival in the thymic microenvironment. J Immunol 2007, 178:858-868

21. Pui JC, Allman D, Xu L, DeRocco S, Karnell FG, Bakkour S, Lee JY, Kadesch T, Hardy RR, Aster JC, Pear WS: Notch1 expression in early lymphopoiesis influences B versus T lineage determination. Immunity 1999, 11:299-308

22. Okajima T, Irvine KD: Regulation of notch signaling by o-linked fucose. Cell 2002, 111:893-904

23. Okajima T, Xu A, Irvine KD: Modulation of notch-ligand binding by protein O-fucosyltransferase 1 and fringe. J Biol Chem 2003, 278:42340-42345

24. Bruckner K, Perez L, Clausen H, Cohen S: Glycosyltransferase activity of Fringe modulates Notch-Delta interactions. Nature 2000, 406:411-415

25. Rampal R, Arboleda-Velasquez JF, Nita-Lazar A, Kosik KS, Haltiwanger RS: Highly conserved O-fucose sites have distinct effects on Notch1 function. J Biol Chem 2005, 280:32133-32140

26. Duncan AW, Rattis FM, DiMascio LN, Congdon KL, Pazianos G, Zhao C, Yoon K, Cook JM, Willert K, Gaiano N, Reya T: Integration of Notch and Wnt signaling in hematopoietic stem cell maintenance. Nat Immunol 2005, 6:314-322

27. Adolfsson J, Borge OJ, Bryder D, Theilgaard-Monch K, AstrandGrundstrom I, Sitnicka E, Sasaki Y, Jacobsen SE: Upregulation of Flt3 expression within the bone marrow Lin(-)Sca1(+)c-kit(+) stem cell compartment is accompanied by loss of self-renewal capacity. Immunity 2001, 15:659-669

28. Adolfsson J, Mansson R, Buza-Vidas N, Hultquist A, Liuba K, Jensen CT, Bryder D, Yang L, Borge OJ, Thoren LA, Anderson K, Sitnicka E, Sasaki Y, Sigvardsson M, Jacobsen SE: Identification of Flt3+ Iympho-myeloid stem cells lacking erythro-megakaryocytic potential a revised road map for adult blood lineage commitment. Cell 2005, 121:295-306

29. Laiosa CV, Stadtfeld M, Xie H, de Andres-Aguayo L, Graf T: Reprogramming of committed $T$ cell progenitors to macrophages and dendritic cells by C/EBP alpha and PU. 1 transcription factors. Immunity 2006, 25:731-744

30. Schmitt TM, Zuniga-Pflucker JC: Induction of T cell development from hematopoietic progenitor cells by delta-like-1 in vitro. Immunity 2002, 17:749-756

31. Man Y: Novel developmental, cellular and biochemical functions of fucosylated glycans in mammals (master's thesis). [Ann Arbor (MI)]: University of Michigan

32. Pear WS, Aster JC, Scott ML, Hasserjian RP, Soffer B, Sklar J, Baltimore $D$ : Exclusive development of $\mathrm{T}$ cell neoplasms in mice transplanted with bone marrow expressing activated Notch alleles. J Exp Med 1996, 183:2283-2291

33. Luo Y, Nita-Lazar A, Haltiwanger RS: Two distinct pathways for Ofucosylation of epidermal growth factor-like or thrombospondin type 1 repeats. J Biol Chem 2006, 281:9385-9392

34. Swiatek PJ, Lindsell CE, del Amo FF, Weinmaster G, Gridley T: Notch1 is essential for postimplantation development in mice. Genes Dev 1994, 8:707-719

35. Huppert SS, Le A, Schroeter EH, Mumm JS, Saxena MT, Milner LA, Kopan R: Embryonic lethality in mice homozygous for a processingdeficient allele of Notch1. Nature 2000, 405:966-970

36. Shi S, Stanley P: Protein O-fucosyltransferase 1 is an essential component of Notch signaling pathways. Proc Natl Acad Sci U S A 2003, 100:5234-5239

37. Becker DJ, Lowe JB: Fucose: biosynthesis and biological function in mammals. Glycobiology 2003, 13:41R-53R

38. Haltiwanger RS, Lowe JB: Role of glycosylation in development. Annu Rev Biochem 2004, 73:491-537
39. Zou GM, Chen JJ, Yoder MC, Wu W, Rowley JD: Knockdown of Pu. 1 by small interfering RNA in CD34+ embryoid body cells derived from mouse ES cells turns cell fate determination to pro-B cells. Proc Natl Acad Sci U S A 2005, 102:13236-13241

40. Saito T, Chiba S, Ichikawa M, Kunisato A, Asai T, Shimizu K, Yamaguchi T, Yamamoto G, Seo S, Kumano K, Nakagami-Yamaguchi E, Hamada Y, Aizawa S, Hirai H: Notch2 is preferentially expressed in mature B cells and indispensable for marginal zone B lineage development. Immunity 2003, 18:675-685

41. Christensen JL, Weissman IL: Flk-2 is a marker in hematopoietic stem cell differentiation: a simple method to isolate long-term stem cells. Proc Natl Acad Sci U S A 2001, 98:14541-14546

42. Forsberg EC, Prohaska SS, Katzman S, Heffner GC, Stuart JM, Weissman IL: Differential expression of novel potential regulators in hematopoietic stem cells. PLoS Genet 2005, 1:e28

43. Friedman AD: Transcriptional regulation of granulocyte and monocyte development. Oncogene 2002, 21:3377-3390

44. Anderson MK, Weiss AH, Hernandez-Hoyos G, Dionne CJ, Rothenberg EV: Constitutive expression of PU. 1 in fetal hematopoietic progenitors blocks T cell development at the pro-T cell stage. Immunity 2002, 16:285-296

45. Sasamura T, Ishikawa HO, Sasaki N, Higashi S, Kanai M, Nakao S, Ayukawa T, Aigaki T, Noda K, Miyoshi E, Taniguchi N, Matsuno K: The O-fucosyltransferase O-fut1 is an extracellular component that is essential for the constitutive endocytic trafficking of Notch in Drosophila. Development 2007, 134:1347-1356

46. Kim YW, Koo BK, Jeong HW, Yoon MJ, Song R, Shin J, Jeong DC, Kim SH, Kong YY: Defective Notch activation in microenvironment leads to myeloproliferative disease. Blood 2008, 112:4628-4638

47. Harris RJ, Spellman MW: O-linked fucose and other post-translational modifications unique to EGF modules. Glycobiology 1993, 3:219-224

48. Moloney DJ, Shair LH, Lu FM, Xia J, Locke R, Matta KL, Haltiwanger RS: Mammalian Notch1 is modified with two unusual forms of Olinked glycosylation found on epidermal growth factor-like modules. J Biol Chem 2000, 275:9604-9611

49. Schiffer SG, Foley S, Kaffashan A, Hronowski X, Zichittella AE, Yeo CY, Miatkowski K, Adkins HB, Damon B, Whitman M, Salomon D, Sanicola M, Williams KP: Fucosylation of Cripto is required for its ability to facilitate nodal signaling. J Biol Chem 2001, 276:37769-37778

50. Yan YT, Liu JJ, Luo Y, E C, Haltiwanger RS, Abate-Shen C, Shen MM: Dual roles of Cripto as a ligand and coreceptor in the nodal signaling pathway. Mol Cell Biol 2002, 22:4439-4449

51. Gonzalez de Peredo A, Klein D, Macek B, Hess D, Peter-Katalinic J, Hofsteenge J: C-mannosylation and o-fucosylation of thrombospondin type 1 repeats. Mol Cell Proteomics 2002, 1:11-18

52. Hofsteenge J, Huwiler KG, Macek B, Hess D, Lawler J, Mosher DF Peter-Katalinic J: C-mannosylation and O-fucosylation of the thrombospondin type 1 module. J Biol Chem 2001, 276:6485-6498

53. Chen H, Herndon ME, Lawler J: The cell biology of thrombospondin-1. Matrix Biol 2000, 19:597-614

54. Stahl M, Uemura K, Ge C, Shi S, Tashima Y, Stanley P: Roles of Pofut1 and O-fucose in mammalian Notch signaling. J Biol Chem 2008, 283:13638-13651

55. Shi S, Ge C, Luo Y, Hou X, Haltiwanger RS, Stanley P: The threonine that carries fucose, but not fucose, is required for Cripto to facilitate Nodal signaling. J Biol Chem 2007, 282:20133-20141

56. Vercauteren SM, Sutherland HJ: Constitutively active Notch4 promotes early human hematopoietic progenitor cell maintenance while inhibiting differentiation and causes lymphoid abnormalities in vivo. Blood 2004, 104:2315-2322

57. Bell JJ, Bhandoola A: The earliest thymic progenitors for $T$ cells possess myeloid lineage potential. Nature 2008, 452:764-767

58. Mercher T, Cornejo MG, Sears C, Kindler T, Moore SA, Maillard I, Pear WS, Aster JC, Gilliland DG: Notch signaling specifies megakaryocyte development from hematopoietic stem cells. Cell Stem Cell 2008, 3:314-326

59. Scadden DT: The stem-cell niche as an entity of action. Nature 2006 , 441:1075-1079

60. Wilson A, Trumpp A: Bone-marrow haematopoietic-stem-cell niches. Nat Rev Immunol 2006, 6:93-106 